\title{
ON THE TRADE-OFF BETWEEN EFFICIENCY IN JOB ASSIGNMENT AND TURNOVER: THE ROLE OF BREAKUP FEES*
}

\author{
ARIJIT MUKHERJEE ${ }^{\dagger}$ AND LUÍS VASCONCELOS $\ddagger$
}

\begin{abstract}
We highlight a novel trade-off with the use of breakup fees in employment contracts. Under asymmetric learning about workers' productivity, the market takes job assignments (or "promotions") as a signal of quality and bids up the wages of a promoted worker, leading to inefficiently few promotions (Waldman, 1984). Breakup fees can mitigate such inefficiencies by shielding the firm from labor-market competition, but they reduce turnover efficiency when there are firm-specific matching gains. We show that it is optimal to use breakup fees if and only if the difference between the worker's expected productivity in the pre- and post-promotion jobs is small. Also, the relationship between the optimality of breakup fees and the importance of firm-specific human capital is more nuanced than what the extant literature may suggest.
\end{abstract}

\section{IntRoduCtion}

Firms often incorporate breakup fees into their employment contracts in order to dissuade their workers from moving to competing employers. Such breakup fees, also known as "golden handcuffs," are a contractual obligation for the employee to pay back a part of his compensation (or to pay a "damage" fee) to the firm if he leaves to join a rival. For example, deferred compensation plans such as retirement benefits and stock options with gradual vesting force the employee to forfeit a portion of his compensation if he quits sooner than later. Another common form of employment contracts with a steep breakup fee is the contracts with the so-called "non-compete clause" where, for a certain duration of time, the worker is contractually prohibited from taking up employment with a competitor. Should the worker decide to move while the clause is still in effect, he may make a buyout offer in order to release himself from any legal obligations. ${ }^{1}$

Date: October 17, 2017.

${ }^{*}$ We especially thank Jay Pil Choi, Carl Davidson, Suman Ghosh, Charles Hadlock, Maria Goltsman, Larry Martin, José Mata, Guillaume Roger, Gary Solon, Michael Waldman, Jan Zabojnik and the seminar participants at Florida Atlantic University, Freie Universität Berlin, London Business School, Michigan State University, RAND Corporation, University of Essex, University of Southern California, and University of Western Ontario. Any errors that may remain are ours.

${ }^{\dagger}$ Department of Economics, Michigan State University, 110 Marshall Adams Hall, East Lansing, MI 48823, USA. Email: arijit@msu.edu. URL: www.amukherjee.net.

${ }^{\ddagger}$ Department of Economics, University of Essex, Wivenhoe Park, Colchester, CO4 3SQ, UK. E-mail: lvasco@essex.ac.uk.

${ }^{1}$ There is strong empirical evidence that breakup fees are effective in reducing employee turnover. Mehran and Yermack (1997) find that stock options can reduce CEO turnover (see also, Jackson and Lazear, 1991, and Scholes, 1991). Allen et al. (1993) find similar effects of deferred compensation through pension plans. Manchester (2009) and Hoffman and Burks (2013) show the effectiveness of "training contracts" under which an employee must reimburse her cost of training to the firm should she decide to leave. Analyzing the career patterns of top executives, Garmaise (2011) finds that non-compete clauses also help reduce the turnover rate. 
In recent years, the use of non-compete clauses has proliferated in a wide range of industries. A large majority of managerial and technical employees at all levels of the organizational hierarchy are estimated to have signed contracts that include some form of non-compete clause (Lobel, 2013, p. 51). It is also interesting to note that contractual restrictions on workers' mobility are becoming commonplace at a time when the recent growth in recruiting networks (e.g., staffing agencies, social media sites such as LinkedIn, etc.) has made a worker's career progress within a firm - i.e., his job assignments or promotions - more visible to outsiders.

The current literature on breakup fees (including non-compete clauses) argues for their effectiveness in protecting proprietary knowledge and in sharpening a firm's incentives to invest in human capital. But it fails to explain the widespread use of such clauses in industries where such concerns are not relevant (Lobel, 2013). Also, it cannot justify the aforementioned contemporaneity between the use of such contracts and the increased visibility of workers' career progress. In this article, we present a novel justification for the use of breakup fees that abstracts away from the issues of investment or knowledge protection and is also consistent with the simultaneity between the rise in the use of such fees and the increased visibility of the workers' career path.

We consider an environment with asymmetric learning on workers' productivity, in which the outside labor market takes the workers' job assignments (or promotions) as a signal of their productivity. As shown by Waldman (1984), such signaling implications of job assignments leads to inefficiently fewer promotions. We argue that breakup fees can mitigate such inefficiencies. However, in the presence of firm-specific matching gains, breakup fees may also reduce efficiency in worker turnover. We analyze the optimality of breakup fees in light of this trade-off.

We explore this trade-off by using a simple two-period principal-agent model where the firm (principal) has two types of job, 1 and 2 . In period one, the firm hires an agent with unknown ability and assigns him to job 1 . The initial contract specifies a wage for period one and a breakup fee payable to the firm should the worker decide to leave for a competitor in the future. In period two, the firm privately observes the worker's ability and decides whether to promote him to job 2. The workers with higher ability are more productive in job 2 compared to job 1 . Once the promotion decision is made, it is publicly observed and multiple firms in the outside labor market - with whom the worker might be better matched - compete in wages to bid away the worker. The initial employer can make a counteroffer upon observing external recruiters' bids. The firm offers a period-two wage if it prefers to retain the worker. Otherwise, it lets the worker go and collects the breakup fee. However, the firm may renegotiate and lower the fee if it prefers to do so.

As workers with higher ability are more likely to be promoted, and a worker's promotion is more visible publicly than his actual ability, job assignment becomes a signal of quality. However, as just noted, this signaling implication of promotion distorts efficiency in job assignment (Waldman, 1984). The outside labor market takes promotion as a signal of high quality of a worker and it may try to bid him away by offering a higher wage. Since competition bids up the wage of a promoted worker, a firm only promotes a worker if he would be sufficiently more productive in job 2 that he would be worth the higher wage that comes with a promotion. Consequently, too few workers are promoted compared with what 
would be socially efficient. ${ }^{2}$ Breakup fees can mitigate such inefficiencies by creating a wedge between what the market offers to a promoted worker and what the firm must pay to retain him - the worker stays back as long as the market's bid net of the breakup fee is dominated by his current wage offer. Consequently, promotion becomes less expensive (for the firm) and the firm has a stronger incentive to promote the worker.

But on the other hand, the use of breakup fee reduces the efficiency in turnover: When a breakup fee is in place, the firm is more likely to retain a worker even when he is better matched with the external recruiters. As the firm lowers its promotion threshold, promotion becomes a weaker signal of quality. As a result, the market reduces its bid for the worker and the firm may find it more profitable to retain him by making a counteroffer. The inefficiency in turnover is detrimental to the firm (ex-ante) since the firm could extract the matching gains up-front from the worker.

We show that the optimality of a breakup fee depends on the relative size of the worker's expected productivity in the two jobs inside the firm. It is optimal to specify a breakup fee if and only if the difference between the worker's expected productivity in the two jobs is not too large. Moreover, when the use of breakup fee is optimal for the firm, it is also socially optimal (i.e., it increases the aggregate social surplus).

The intuition for this finding is as follows. When the difference between the workers' expected productivity in the two jobs is large, the firm already has a strong incentive to promote them as they would be much more productive in job 2 than in job 1 . Workers who are inefficiently kept in job 1 are of low ability and thus would have had small productivity gains had they been assigned to job 2. Thus, in such a setting, the marginal gains from the more efficient promotion that is brought about by stipulating a breakup fee would be relatively small. In fact, such a breakup fee would hinder the efficient turnover of the promoted workers by lowering the external recruiters' bid, and the marginal loss due to inefficient turnover would be relatively large. (We argue later that there is no net change in ex-ante turnover efficiency for workers who are not promoted.) Consequently, it is optimal not to stipulate such a fee.

By contrast, when the difference between expected productivity in the two jobs is relatively small, the firm would promote very few workers - only those with sufficiently high ability. In addition, a marginal worker who was denied promotion would have been considerably more productive if promoted. Thus, the marginal gain from the improved job assignment is high, while the marginal loss from reduced turnover is low. Therefore, it becomes optimal to stipulate a breakup fee, since this eases inefficiency in promotion but costs little in terms of any turnover inefficiency that it creates.

Our findings on the effects and the optimality of breakup fees have some important implications. First, we offer a novel justification for the use of breakup fees even in situations where the oft-cited benefits of such fees - protection of investment or proprietary knowledge - are not relevant. Furthermore, as asymmetric learning about worker quality is a key driver of the above findings, they suggest that breakup fees are more likely to be used where information about workers' quality remains private (to the initial employer) but information about job

\footnotetext{
${ }^{2}$ Several authors have offered empirical evidence of the signaling role of job assignment and the resulting distortions as predicted in Waldman (1984). See, for example, DeVaro and Waldman (2012), Bognanno and Melero (2016), and Cassidy et al. (2016). Dato et al. (2016) also shows similar evidence in experimental labor markets. See also Baker et. al (1994a, 1994b) and McCue (1996) for empirical evidence that promotion is often associated with large wage increases.
} 
assignments becomes public. Indeed, breakup fees need not be used by firms when workers' promotions are not visible to the market or when workers' productivity is perfectly observed by the market. This observation is consistent with the simultaneous rise in the use of restrictive covenants and the visibility of workers' career progress within firms in the U.S. labor market, as mentioned earlier.

Second, we highlight how the optimality of breakup fees is linked to the underlying production technologies in an organizational hierarchy. To the best of our knowledge, such a link has not been explored hitherto in the literature. An interesting implication of our result is that breakup fees are less likely to be used when the nature of the pre- and post-promotion jobs is significantly different. Such a difference is likely to imply a large variation in the worker's productivity as well.

Finally, our findings also contribute to the debate on the enforcement of employment contracts that attempt to restrict turnover. For example, in the U.S., courts often refrain from enforcing a non-compete clause, citing harm from restricted labor mobility (Lobel, 2013; Malsberger, 2004). However, in our setting, the court should always enforce a contract with breakup fee: If the fee is optimal for the firm, then it is also optimal for social welfare.

We also analyze the role of firm-specific human capital in determining the optimality of breakup fees. The extant literature suggests that the distortion in job-assignment is smaller when firm-specific human capital plays a bigger role in the worker's productivity (Waldman, 1984, 2013; Ghosh and Waldman, 2010). When firm-specific human capital is important, the worker is more likely to be a better match with his initial employer. Hence, the outside labor market is less likely to bid for him, and the firm has a stronger incentive to promote the worker. In light of this observation one may anticipate that breakup fees are used less often when firm-specific human capital is more important for production. However, we argue that the relationship between the two is more nuanced than what the above intuition may suggest.

In particular, we show that for a given breakup fee (so long as it is not too large), the above intuition continues to hold: The firm is more likely to promote a worker as firmspecific human capital becomes more important. But there is a countervailing effect. As firm-specific human capital becomes more important, the promotion policy that maximizes the firm's expected profit also calls for promoting more workers. Consequently, the firm stipulates a higher breakup fee ex-ante to ensure a stronger incentive for promoting a worker ex-post. It is interesting to note, however, that this result may not hold if we assume that the outside labor market never bids for workers who are not promoted, as they may not be visible to the market. In such an environment it is indeed the case that the firm is less likely to use breakup fees when firm-specific human capital becomes more critical. In other words, the impact of firm-specific human capital on the use of breakup fees critically hinges on the market visibility of the worker at different tiers of the organizational hierarchy.

Related literature: The extant literature on breakup fees has studied its impact on various aspects of the employment relationship. There is a large literature on the role of deferred compensation in human capital investment (Becker, 1964), tenure (Lazear, 1979), and turnover (Salop and Salop, 1976). More recently, several authors have also shown how a non-compete clause may be used to protect returns on investment in human capital (Rubin and Shedd, 1981; Posner et. al, 2004; Bishara, 2006), to restrict the diffusion of proprietary knowledge (Franco and Filson, 2006), to reduce turnover (Kräkel and Sliwka, 2009; Garmaise, 
2011; Mukherjee and Vasconcelos, 2012), and to discourage employee spinoffs (Franco and Mitchell, 2008; Rauch and Watson, 2015).

By contrast, this article highlights a different trade-off that arises with the use of breakup fees: Such fees improve the efficiency in job assignments but they hinder efficient turnover. The environment in which this trade-off occurs has two salient features, both of which are well documented in the current literature. (i) Asymmetric information among employers leads to inefficient turnover (Greenwald, 1986; Lazear, 1986; Gibbons and Katz, 1991; Laing, 1994; also see Gibbons and Waldman, 1999, for a survey). (ii) The initial employer's (publicly observable) decisions - e.g., promotions, outcome of a rank-order tournament, etc.,-may signal the outside labor market regarding a worker's quality (Waldman, 1984, 1990; Bernhardt and Scoones, 1993; Zábojník and Bernhardt, 2001; Golan, 2005; Mukherjee, 2008; Ghosh and Waldman, 2010; Koch and Peyrache, 2011).

As discussed earlier, our paper is closely related to Waldman (1984). In a framework similar to Waldman (1984), Bernhardt and Scoones (1993) consider a more general model of promotion and turnover in the presence of firm-specific matching gains. They assume that external recruiters can invest to acquire information on the workers' quality and argue that in order to dissuade the external recruiters from doing so (since this increases turnover), a firm may offer a preemptively high wage when promoting a worker. The wage signals a potentially good match between the worker and the current firm, and it discourages external recruiters from acquiring information (as they anticipate a lower likelihood of successful bid). The assumption that the outside market can acquire the exact same information that the initial employer possesses is crucial for this finding. In our model, such direct information acquisition is not feasible and the initial employer always enjoys some degree of information advantage.

Another article that is closely related to ours is Burguet et al. (2002). They study the link between the level of transparency about worker's ability and the use of breakup fees. In their setting, such fees help the firm to extract matching gains from the recruiters. They argue that the firm would stipulate a larger breakup fee when a worker's ability was public information as the market bids more aggressively when there is no adverse selection in turnover. This result is in sharp contrast to our findings, as in our case no breakup fee is necessary when the worker's ability is public information.

The role of breakup fee in our model is similar in spirit to that of restrictive covenants in the setup considered by Rauch and Watson (2015). In a model of employee spinoffs in client service firms, Rauch and Watson show that a restrictive covenant can create a favorable default option for the firm for future negotiations if the employee threatens to start a spinoff by stealing the firm's clients. But even though the covenant protects the firm from losing its clients, it could be socially inefficient, as it thwarts the formation of efficient spinoffs. In our model, the breakup fee also ensures a favorable default option for the firm when there is turnover. In the process, it also protects the firm from labor-market competition. While such a fee distorts turnover and perpetuates poor firm-worker match, it does improve efficiency in job assignment. Moreover, in our setting, if a breakup fee is profitable for the firm, then it is socially optimal as well.

Finally, it is also worth noting that our model is reminiscent of Laing (1994). Laing argues that asymmetric learning about worker quality may distort a firm's layoff decisions when workers are risk-averse. As laid-off workers are perceived as "inferior," the spot market 
competition creates a wedge between laid-off and retained workers' wages, leading to inefficient risk-sharing between the firm and the worker, which, in turn, distorts the firm's lay-off decisions. However, Laing's model abstracts from the job-assignment issue as all workers are placed in the same job.

The rest of the paper is organized as follows. Section 2 presents our model, while Section 3 characterizes the firm's equilibrium job assignment policy and worker turnover for a given breakup fee. In Section 4, we elaborate on the trade-off between inefficiencies in job assignment and turnover. The optimal breakup fee is discussed in Section 5. Section 6 discusses some modeling extensions, including the role of firm-specific human capital. A final section draws a conclusion. All proofs are given in the Appendix.

\section{THE MODEL}

We consider a two-period principal-agent model that is described below in terms of its five key components: players, technology, contracts and job assignment, external offers and counteroffer, and payoffs.

Players. A firm (or "principal"), $F$, hires a worker (or "agent"), $A$, at the beginning of period one. The worker works for the firm in the first period of his life, but in period two he may leave for a different employer as two identical firms in the external labor market (or external "recruiters"), $R_{1}$ and $R_{2}$, bid competitively for him.

Technology. The technology specification of the firm is similar in spirit to that in Waldman (1984). The firm has two types of jobs: job 1 and job 2. Job 1 is the entry level job where the worker is assigned in period one. The worker's productivity in job 1 is assumed to be fixed at $\psi_{1}(>0)$. However, in job 2 the worker's productivity depends on his ability, or "type", $a \in[0,1]$ : if assigned to job 2 (with the firm) a worker of ability $a$ produces $\psi_{2} a$ (where $\psi_{2}>0$ ).

At the beginning of period one, the worker's ability $(a)$ is unknown to all players (including the worker himself), and it is assumed to follow a uniform distribution on $[0,1]$. But at the end of period one, $a$ is observed by the firm (but not by external recruiters or the worker). The information on $a$ is non-verifiable, and hence, the firm cannot credibly disclose it to a third party.

Job 1 is not available with the external recruiters, but they can employ the worker in job $2{ }^{3}$ The worker's productivity with the recruiters depends not only on his ability but also on a matching factor, $m$, and is given by $\psi_{2} a(1+m)$. The matching factor $m$ is unknown to all players at the beginning of the game, and it is assumed to be distributed on $[-1,1]$ according to a piece-wise uniform probability density function $g(m)$, where

$$
g(m)=\left\{\begin{array}{lll}
\alpha & \text { if } & m \leq 0 \\
1-\alpha & \text { if } & m>0
\end{array}\right.
$$

and $\alpha \in[1 / 2,1)$. The associated cumulative distribution function is given by $G(m)$. Note that $m \leq 0$ - an event that occurs with probability $\alpha$-implies that the worker is a better

\footnotetext{
${ }^{3}$ The main trade-off that we highlight in the paper continues to hold even if job 1 is available with the external recruiters, but we maintain this assumption to simplify the exposition. We will revisit this issue, along with the discussion of related modeling choices, later in Section 6.2.
} 
match with his initial employer than with external recruiters. The parameter $\alpha$ can be interpreted as the measure for the importance of firm-specific human capital in job 2. The more critical is the role of the firm-specific human capital in job 2, the less likely it is that the worker would be a better match with the recruiters. The value of $m$ is revealed in period two; we will elaborate on this shortly.

We impose the following restriction on the parameters.

Assumption 1. $\frac{\psi_{1}}{\psi_{2}} G\left(2 \frac{\psi_{1}}{\psi_{2}}-1\right) \leq \alpha$.

This assumption implies that the ratio $\psi_{1} / \psi_{2}$ cannot be too large, and it simplifies our subsequent analysis by ruling out certain corner solutions in the firm's optimal contracting problem.

INITIAL CONTRACT AND JOB ASSIGNMENT. We assume that long-term contracts on wages are not feasible. Also, as the worker's ability $(a)$ is neither observable nor verifiable to a third party, the firm cannot commit to a promotion policy that is contingent on $a$. Hence, we restrict attention to the following class of contracts: At the beginning of period one, the firm makes a take-it-or-leave-it offer $\left(w_{1}, d\right)$ to the worker where $w_{1}$ is the period-one wage and $d$ is a breakup fee that the worker must pay to the firm if he decides to leave for the external recruiters in period two. ${ }^{4}$ At the end of period one, after observing $a$, the firm decides whether to assign (or "promote") the worker to job 2. Both the initial contract $\left(w_{1}, d\right)$ at the beginning of period one and the subsequent job assignment at the end of period one are publicly observed.

EXTERnAl OFFERS AND COUNTEROFFER. At the beginning of period two, external recruiters $\left(R_{1}\right.$ and $\left.R_{2}\right)$ observe the worker's job assignment $(j \in\{1,2\})$ as well as the matching factor $m$, and make simultaneous wage bids $b_{i}(i=1,2)$ for him. ${ }^{5}$ We will maintain the convention that $b_{i}=0$ when recruiter $R_{i}$ refrains from bidding.

Observing the bids, the firm makes a counteroffer to the worker, that consists of a periodtwo wage $w_{2}^{j}$ and a (potentially) renegotiated breakup fee $d_{R}$. Without loss of generality, we consider two types of counteroffer, depending on whether the firm decides to retain the worker or to let him go. If the firm decides to retain the worker (who has been assigned to job $j$ ), it leaves the breakup fee unchanged (i.e., $d_{R}=d$ ) and offers a period-two wage of $w_{2}^{j}$ such that the worker finds it worthwhile to stay with the firm rather than to join a recruiter and pay the fee. And if the firm prefers to let the worker leave, it offers $w_{2}^{j}=0$, and it either leaves the breakup fee unchanged (i.e., $d_{R}=d$ ) or renegotiates it down (i.e., $d_{R}<d$ ) so that

\footnotetext{
${ }^{4}$ Even though we model the payment $d$ as a breakup fee, with a slight modification to our setup, we can reinterpret this payment as a deferred compensation, and all our findings would continue to hold. In particular, we may assume that $d$ is simply a part of the worker's period-one wage that is paid at the end of period two in addition to a non-negative period-two wage, provided that the worker continues to work for the firm. In other words, a firm commiting to a deferred payment $d$ is contractually obligated to pay the worker at least $d$ (as total compensation) in period two if he stays with the firm.

${ }^{5}$ That $m$ is revealed to the recruiters after the firm makes its promotion decision is assumed only for modeling convenience. For the purpose of our analysis, the key assumption is that $m$ is not known to the firm when it makes the promotion decision. This is a natural assumption in many environments where the initial employer may not have complete information on the productivity of his worker (or even on job vacancies) in a competing firm, and this information is revealed only after the worker generates offers from the potential recruiters.
} 
the worker finds it worthwhile to leave for the recruiter after paying $d_{R}$ to the firm rather than to stay back.

The worker chooses the employer who offers the highest wage net of the (potentially renegotiated) breakup fee. We assume that if the worker is indifferent between staying or leaving, he stays with the firm.

PAYOFFs. All players are risk neutral and do not discount the future. Upon successfully hiring a worker $(A)$ of ability $a$, the firm's $(F)$ payoff in period one is $\pi_{1}=\psi_{1}-w_{1}$, and in period two is

$$
\pi_{2}= \begin{cases}\psi_{1}-w_{2}^{1} & \text { if } A \text { is not promoted and retained } \\ \psi_{2} a-w_{2}^{2} & \text { if } A \text { is promoted to job } 2 \text { and retained } \\ d_{R} & \text { if } A \text { is hired by an external recruiter }\end{cases}
$$

Similarly, the worker's payoff in period one is $u_{1}=w_{1}$, and in period two is

$$
u_{2}=\left\{\begin{array}{ll}
b_{i}-d_{R} & \text { if } A \text { joins recruiter } i \\
w_{2}^{j} & \text { if } A \text { stays with } F \text { in job } j
\end{array} .\right.
$$

Let $\Pi:=\pi_{1}+\pi_{2}$ and $U:=u_{1}+u_{2}$ be the aggregate payoffs of the firm and the worker respectively. Finally, recruiter $R_{i}$ 's payoff from a worker with ability $a$ is

$$
\pi_{R_{i}}=\left\{\begin{array}{ll}
\psi_{2} a(1+m)-b_{i} & \text { if } R_{i} \text { successfully recruits } A \\
0 & \text { otherwise }
\end{array} .\right.
$$

We assume that both the worker and the firm have a reservation payoff of 0 .

Time Line. The following time line summarizes the game described above.

- Period 1.0. $F$ publicly offers a contract $\left(w_{1}, d\right)$ to $A$. If accepted, the game proceeds but ends otherwise.

- End of Period 1. Period-one output is realized and period-one wage $\left(w_{1}\right)$ is paid. $F$ privately observes $A$ 's ability $(a)$ and decides on job assignment.

- Period 2.0. $R_{1}$ and $R_{2}$ observe job assignment as well as the matching factor $m$ and simultaneously bid $\left(b_{1}\right.$ and $\left.b_{2}\right)$ for $A$.

- Period 2.1. After observing the bids, $F$ makes a counteroffer $\left(w_{2}^{j}, d_{R}\right)$. If $F$ decides to retain $A, w_{2}^{j} \geq 0$ and $d_{R}=d$, but if $F$ prefers to let $A$ leave, $w_{2}^{j}=0$ and $d_{R} \leq d$ (i.e., the breakup fee may be "renegotiated" down).

- Period 2.2. A chooses which employment contract to accept; pays $d_{R}$ to $F$ if he leaves for a recruiter.

- End of Period 2. Period-two output is realized, period-two wage is paid, and the game ends. 
Strategies And EQUilibrium CONCEPT: The firm's strategy, $\sigma_{F}$, has three components: (i) at the beginning of period one, choose the initial contract offer $\left(w_{1}, d\right)$, (ii) at the end of period one, decide on job assignment $j \in\{1,2\}$ upon observing the worker's ability, and (iii) at the beginning of period two, upon observing the external recruiters' bids, decide on the counteroffer $\left(w_{2}^{j}, d_{R}\right)$. The worker's strategy, $\sigma_{A}$, has two components: (i) accept or reject the firm's initial contract, and (ii) choose period-two employer given the external recruiters' offer and the firm's counteroffer. Finally, a recruiter's strategy, $\sigma_{R_{i}}$ (for $\left.i=1,2\right)$, is to choose a wage bid $b_{i}$ given the matching factor and the firm's job assignment decision.

We use perfect Bayesian Equilibrium (PBE) as a solution concept (as defined in Fudenberg and Tirole, 2000; also see Watson, 2016, for a general definition of PBE that is applicable to a larger class of games). ${ }^{6}$ Note that in a PBE, the external recruiters' posterior belief in the continuation game is obtained through Bayes rule even when the firm deviates from its initial contract offer. Thus, an equilibrium strategy profile (and belief) must induce a PBE in every continuation game following any initial offer $\left(w_{1}, d\right)$, and the optimal breakup fee is simply the one that induces the highest PBE payoff in the continuation game. In what follows, we analyze the optimal contracting problem accordingly.

\section{Job ASSIGNMENT AND TURNOVER}

In order to derive the optimal contract for the firm, we first need to analyze the players' equilibrium behavior in the continuation game following an initial contract $\left(w_{1}, d\right)$. In what follows, we characterize the firm's equilibrium job assignment policy and worker turnover for any arbitrary value of $d$ specified in period one. Notice that the wage in period one, $w_{1}$, has no impact on the firm's decision to promote the worker or on external recruiters' decisions in period two. Hence, it is ignored in the analysis below.

3.1. An efficiency benchmark. We begin our analysis by characterizing the promotion rule that maximizes the aggregate surplus assuming that following the job assignment decision, turnover is always efficient (i.e., the worker leaves whenever he is a better match with an external recruiter). The expected surplus generated by a worker with ability a (assuming efficient turnover) when he is promoted $\left(S_{P}\right)$ and when he is not $\left(S_{N}\right)$ are given as:

\footnotetext{
${ }^{6}$ Formally, in our framework, a PBE is defined as follows: Given the initial contract $\left(w_{1}, d\right)$ and the subsequent job assignment $j \in\{1,2\}$, let $\mu\left(a \mid\left(w_{1}, d\right), j\right)$ be the posterior belief of the recruiters. A profile of strategies $\sigma^{*}=\left\langle\sigma_{F}^{*}, \sigma_{A}^{*}, \sigma_{R_{1}}^{*}, \sigma_{R_{2}}^{*}\right\rangle$ along with the recruiters' belief $\mu^{*}$ constitute a PBE if (i) $\sigma^{*}$ is sequentially rational given $\mu^{*}$, (ii) on-equilibrium path $\mu^{*}$ is obtained through Bayes rule given the prior belief on ability and the strategies of the players, and (iii) off-equilibrium path $\mu^{*}$ satisfies the following restriction. If the firm deviates in period one and offers an initial contract $\left(w_{1}^{\prime}, d^{\prime}\right)$, the posterior belief of the recruiters $\mu^{*}\left(a \mid\left(w_{1}^{\prime}, d^{\prime}\right), j\right)$ must also be obtained through Bayes rule defined as follows: Given an initial contract $\left(w_{1}^{\prime}, d^{\prime}\right) \in \mathbb{R}^{2}$ and the worker's type $a \in[0,1]$, denote $\sigma_{F}^{* J}: \mathbb{R}^{2} \times[0,1] \rightarrow\{1,2\}$ as the component of the firm's strategy $\sigma_{F}^{*}$ that defines the firm's job assignment decision. We require

$$
\mu^{*}\left(a \mid\left(w_{1}^{\prime}, d^{\prime}\right), j\right)=\frac{\operatorname{Pr}\left(j \mid a,\left(w_{1}^{\prime}, d^{\prime}\right), \sigma_{F}^{* J}\right) \operatorname{Pr}(a)}{\operatorname{Pr}\left(j \mid\left(w_{1}^{\prime}, d^{\prime}\right), \sigma_{F}^{* J}\right)} .
$$

Also, the worker's belief on his ability remains unaffected by the firm's initial offer. Note that the restriction on the off-equilibrium belief invokes the "no signaling what you don't know" and "use of Bayes rule whenever possible" conditions suggested by Fudenberg and Tirole $(2000)$. The initial contract $\left(w_{1}, d\right)$ does not affect beliefs on ablility as it is offered before the ability is revealed. Also, in every continuation game following any initial contract offer by the firm, the recruiters update their beliefs using Bayes rule given their (common) prior belief and the firm's job assignment decision (under his strategy $\sigma_{F}^{* J}$ given the initial contract $\left(w_{1}, d\right)$ ).
} 


$$
S_{P}(a)=\mathbb{E}_{m}\left[\max \left\{\psi_{2} a, \psi_{2} a(1+m)\right\}\right] \text { and } S_{N}(a)=\mathbb{E}_{m}\left[\max \left\{\psi_{1}, \psi_{2} a(1+m)\right\}\right]
$$

Notice that the worker's expected productivity with an external recruiter is independent of his job assignment within the current firm. Thus, in order to obtain the promotion rule that maximizes aggregate surplus (when turnover is efficient), one only needs to compare the worker's productivity in the two jobs when he stays with the current firm. So, $S_{P}(a) \geq S_{N}(a)$ if and only if $a \psi_{2} \geq \psi_{1}$. Thus, the efficient promotion rule is to promote a worker of ability $a$ if and only if:

$$
a \geq \frac{\psi_{1}}{\psi_{2}}\left(=: a^{E}\right)
$$

In what follows, the threshold $a^{E}$ serves as a benchmark for evaluating the extent of allocative inefficiency in equilibrium where the private observability of ability leads to inefficiencies in turnover as well as in the firm's job assignment decisions.

3.2. Equilibrium job assignment and turnover (given $d$ ). We now analyze equilibrium job assignment and turnover and explore how the extent of inefficiency is affected by the breakup fee.

As the firm cannot commit to a promotion rule, at the end of period 1 the firm promotes a worker if and only if it is optimal to do so, given the worker's ability and the offer-counteroffer game that follows in period 2. As in our benchmark analysis above, the firm's promotion decision in equilibrium continues to follow a cutoff rule. The argument is straightforward: Recall that the worker's productivity in job 2 is increasing in his ability (i.e., $a \psi_{2}$ ), but in job 1 it is constant (i.e., $\left.\psi_{1}\right)$. Now, since the worker's period-two wage is determined in the spot market, but the external recruiters cannot observe the worker's ability $(a)$, the worker's wage conditional on job assignment is independent of his ability. So the firm's payoff from offering promotion is increasing in $a$ while denying promotion yields a constant payoff. Consequently, the firm promotes a worker if and only if his ability is greater than a cutoff value $a^{*}$ (say).

In what follows, we solve for the equilibrium cutoff ability level $a^{*}$ as a function of the breakup fee $(d)$. Note that if a cutoff $a^{*}$ constitutes an equilibrium promotion policy, the firm must be indifferent to promoting or not promoting a worker with ability $a^{*}$-i.e., the firm's expected payoff from the marginal worker must be the same, irrespective of the worker's job assignment. However, the derivation of the firm's payoff is somewhat involved, as it depends on external recruiters' bids, and these in turn depend on the firm's job assignment and counteroffer decisions. As the equilibrium strategies must be sequentially rational, we derive these payoffs through backward induction.

First, consider the firm's payoff from keeping a worker (including the marginal one) in job 1. We begin our derivation of the firm's payoff by first considering its counteroffer decision. Trivially, if there are no offers from external recruiters (i.e., $b_{i}=0$ for all $i$ ), the firm offers a wage $w_{2}^{1}=0$ to the worker to match his outside option and retains him in job $1 .{ }^{7}$ But if the worker receives an external offer, the firm's counteroffer requires a more careful study.

\footnotetext{
${ }^{7}$ In our setting, the outside option of the worker in period two is the payoff he would get if he left the firm but did not get hired by any external recruiter. By our modeling assumptions, this payoff is zero. That is, we implicitly assume that the firm cannot contractually require a breakup fee from the worker should he leave the firm irrespective of his subsequent employment status. This is a natural assumption since, in practice, any clause in a labor contract that imposes restrictions on the workers' mobility, such as a breakup
} 
Let $b$ denote the highest bid that the worker receives; i.e., $b=\max \left\{b_{1}, b_{2}\right\}$. (Throughout this article we refer to $b$ as the market bid.) Notice that upon receiving a market bid $b$, the worker (assigned in job 1) leaves the firm if and only if $b>\psi_{1}$. When $b \leq \psi_{1}$, the firm retains the worker by offering $\operatorname{him}\left(w_{2}^{1}, d_{R}\right)=(0, d)$ if $b \leq d$ and $\left(w_{2}^{1}, d_{R}\right)=(b-d, d)$ if $b>d$. Notice that in both cases, the firm leaves the breakup fee unchanged. But if $b>\psi_{1}$, the firm lets the worker go, and it collects $\min \{b, d\}$ from the worker as a breakup fee; if $b<d$ the firm renegotiates the breakup fee down and offers $\left(w_{2}^{1}, d_{R}\right)=(0, b)$; and if $b \geq d$, no renegotiation is called for and $\left(w_{2}^{1}, d_{R}\right)=(0, d)$.

Now, moving backwards in the game, consider the external recruiters' bidding strategy for a worker assigned to job 1 given a promotion threshold $a^{*}$ (i.e., where the worker is promoted only if his ability exceeds a cutoff $a^{*}$ ). Since the external recruiters compete for the worker, they make zero expected profit (in equilibrium) and bid the expected value of a worker whom they could successfully recruit (given the firm's counteroffer decision). That is, the external recruiters successfully bid for a worker assigned in job 1 when:

$$
\mathbb{E}_{a}\left[\psi_{2} a(1+m) \mid a \in\left[0, a^{*}\right)\right]=\frac{1}{2} \psi_{2} a^{*}(1+m)>\psi_{1} \Leftrightarrow m>\frac{2 \psi_{1}}{a^{*} \psi_{2}}-1 .
$$

So, the external recruiters' equilibrium wage bids are $b_{1}=b_{2}=b_{N}^{*}$ where:

$$
b_{N}^{*}\left(m ; a^{*}\right)=\left\{\begin{array}{ll}
0 & \text { if } m \leq \frac{2 \psi_{1}}{a^{*} \psi_{2}}-1 \\
\frac{1}{2} \psi_{2} a^{*}(1+m) & \text { if } m>\frac{2 \psi_{1}}{a^{*} \psi_{2}}-1
\end{array} .\right.
$$

Note that $b_{N}^{*}$ is increasing in both $m$ and $a^{*}$. A larger $m$ implies a higher productivity, and hence, leads to a higher bid. A larger $a^{*}$ implies that the firm is more selective in its promotion decision, and hence, the expected ability of the worker who misses promotion also increases. However, the equilibrium bid does not depend on $d$ as it gets renegotiated whenever the firm finds it optimal to do so.

Using $b_{N}^{*}$ we can derive the firm's payoff from keeping the marginal worker in job 1 . From the firm's counteroffer strategy we know that when $b_{N}^{*}\left(m ; a^{*}\right)=0$, the worker stays with the firm and the firm earns $\psi_{1}$; but when $b_{N}^{*}\left(m ; a^{*}\right)>0$, the worker leaves the firm and the firm earns $\min \left\{b_{N}^{*}\left(m ; a^{*}\right), d\right\}$. That is, the firm's payoff (as a function of $m$ and $d$ given $a^{*}$ ) is:

$$
\pi_{N}\left(m, d ; a^{*}\right)=\left\{\begin{array}{ll}
\psi_{1} & \text { if } m \leq \frac{2 \psi_{1}}{a^{*} \psi_{2}}-1 \\
\min \left\{b_{N}^{*}\left(m ; a^{*}\right), d\right\} & \text { otherwise }
\end{array} .\right.
$$

Next, consider the firm's payoff from promoting the marginal worker to job 2. As before, a promoted worker who does not receive any market offer gets $w_{2}^{2}=0$. If the worker receives a market offer of $b$, the firm makes a counteroffer and retains him if $b \leq a \psi_{2}$ but lets him go otherwise by (possibly) renegotiating the breakup fee down to $d_{R}=\min \{b, d\}$.

Observe that external recruiters face a winner's curse problem while bidding for a worker in job 2: A successful bid necessarily implies that the worker's ability is relatively low (i.e.,

fee, must be limited in scope in order to be enforced by courts. At the same time, the court cannot force the worker to continue working for any specific employer. 
$\left.a \in\left[a^{*}, b / \psi_{2}\right)\right)$ as a worker with higher ability would be retained by the firm. ${ }^{8}$ Therefore, the external recruiters' payoff from bidding $b$ for a worker assigned in job 2 (when the promotion cutoff is $\left.a^{*}\right)$ is:

$$
\mathbb{E}_{a}\left[\psi_{2} a(1+m) \mid a \in\left[a^{*}, b / \psi_{2}\right)\right]= \begin{cases}0 & \text { if } b \leq \psi_{2} a^{*} \\ \frac{1}{2} \psi_{2}\left(a^{*}+b / \psi_{2}\right)(1+m) & \text { if } \psi_{2} a^{*}<b<\psi_{2} \\ \frac{1}{2} \psi_{2}\left(a^{*}+1\right)(1+m) & \text { if } b>\psi_{2}\end{cases}
$$

As discussed earlier, by virtue of competition between the external recruiters, their equilibrium bids for a worker in job 2 must satisfy $b_{1}=b_{2}=b_{P}^{*}$ where $b_{P}^{*}$ solves

$$
b=\mathbb{E}_{a}\left[\psi_{2} a(1+m) \mid a \in\left[a^{*}, b / \psi_{2}\right)\right]
$$

That is,

$$
b_{P}^{*}\left(m ; a^{*}\right)= \begin{cases}0 & \text { if } m \leq 0 \\ \psi_{2} a^{*} \frac{1+m}{1-m} & \text { if } 0<m<\frac{1-a^{*}}{1+a^{*}} \\ \frac{1}{2} \psi_{2}\left(a^{*}+1\right)(1+m) & \text { if } m>\frac{1-a^{*}}{1+a^{*}}\end{cases}
$$

The following remarks are in order. First, similar to $b_{N}^{*}, b_{P}^{*}$ is increasing in $m$ and $a^{*}$, and it is independent of $d$ (the reasoning is also the same). Second, the equilibrium bidding strategies (both $b_{N}^{*}$ and $b_{P}^{*}$ ) maintain an implicit assumption that the recruiters do not play weakly dominated strategies. ${ }^{9}$ Finally, in response to the winner's curse problem, the recruiters shade their bids, and the period-two wage of a promoted worker is depressed. Moreover, the recruiters refrain from bidding when a competitive bid is sure to fail (i.e., they choose $b_{N}^{*}=0$ if $m \leq\left(2 \psi_{1} / a^{*} \psi_{2}\right)-1$ and $b_{P}^{*}=0$ if $\left.m \leq 0\right) .{ }^{10}$

The firm's counteroffer strategy and the recruiters' bidding strategies described above imply that the marginal worker (i.e., the one with ability $a^{*}$ ) always receives a market offer and leaves the firm when $m>0$, but stays with the firm at zero wage when $m<0$. Hence the firm's payoff from promoting the marginal worker is:

\footnotetext{
${ }^{8}$ The winner's curse problem with the recruiters' bid has also been highlighted in several other models of job assignment and external offers, e.g., Golan, 2005; DeVaro and Waldman, 2012. In these models, the worker is always a better match with the initial employer and the winner's curse effect ensures that recruiters only bid for the least productive worker who could be promoted. In contrast, in our setting, the equilibrium bids could be higher than the productivity of the marginal type (i.e., $\psi_{2} a^{*}(1+m)$ ), as we allow for the worker to be a better match with the recruiter.

${ }^{9}$ This is a standard assumption in the literature (see, e.g., DeVaro and Waldman, 2012). Otherwise, there may exist other equilibria whereby the recruiters bid more than the expected value of the worker (to the recruiters) if the firm is expected with certainty to retain the worker by making a counteroffer. One may rule out such equilibria as they are not "trembling hand perfect": If there is a small probability that the worker may mistakenly accept the recruiters' bid, then the recruiter is strictly better off not placing a bid that is higher than its valuation for the worker. Such equilibria in dominated strategies also do not survive the "market-Nash" refinement of Waldman (1984).

${ }^{10}$ One may justify this assumption by considering an infinitesimal cost of placing a bid. Hence, if a recruiter is certain that he cannot lure away a worker by bidding the most he can without incurring a loss, he will prefer not to bid for the worker.
} 


$$
\pi_{P}\left(m, d ; a^{*}\right)=\left\{\begin{array}{ll}
\psi_{2} a^{*} & \text { if } m \leq 0 \\
\min \left\{b_{P}^{*}\left(m ; a^{*}\right), d\right\} & \text { otherwise }
\end{array} .\right.
$$

If the cutoff $a^{*}$ constitutes an equilibrium, the firm must have the same (expected) payoff from the marginal worker irrespective of his job assignment. So, $a^{*}$ solves:

$$
\mathbb{E}_{m} \pi_{N}\left(m, d ; a^{*}\right)=\mathbb{E}_{m} \pi_{P}\left(m, d ; a^{*}\right)
$$

Observe that even though the recruiters' bidding strategy does not depend on the breakup fee $d$, the equilibrium promotion rule does. This is because $d$ affects the firm's expected payoffs from the marginal worker in the two jobs. The following proposition characterizes the solution to equation (7) and illustrates how the breakup fee affects the equilibrium ability cutoff for promotion.

Proposition 1. Given a breakup fee $d$, there exists a unique cutoff level $a^{*}(d)$ such that the firm promotes a worker if and only if his ability $a \geq a^{*}(d)$. The cutoff $a^{*}(d)$ is strictly decreasing in $d$ for $d<\hat{d}$ and independent of $d$ for $d \geq \hat{d}$ where $\hat{d} \in\left(\psi_{2}, \psi_{1}+\psi_{2}\right)$. Moreover, $a^{*}(0)>a^{E}\left(=\psi_{1} / \psi_{2}\right)$ and $a^{*}\left(\psi_{1}\right)=a^{E}$.

A key implication of Proposition 1 is that the larger is the associated breakup fee, the more likely the firm is to promote a worker; i.e., the promotion cutoff $a^{*}$ (weakly) decreases in $d$.

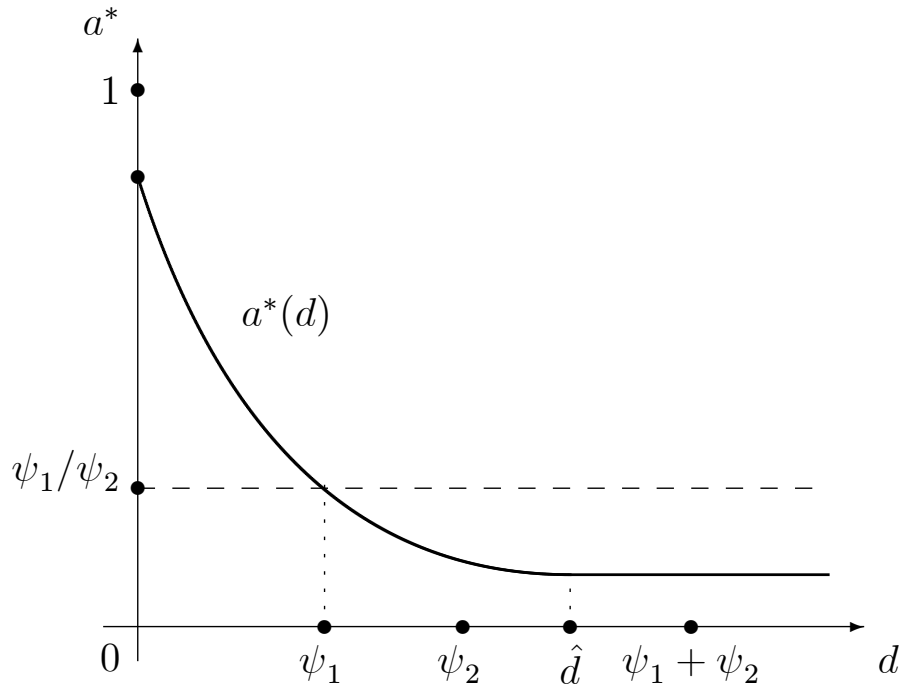

Figure 1. The equilibrium cut-off for promotion as a function of the break-up fee $(d)$.

To see the intuition, notice that the breakup fee affects the surplus the firm can extract from the marginal worker in case there is turnover. In particular, regardless of the firm's job assignment decision, the firm's payoff (i.e., both $\pi_{P}$ and $\pi_{N}$ ) is $d$ when the market recruits the worker by making a relatively large bid. Hence, an increase in $d$ increases the firm's expected 
payoff from the marginal worker irrespective of his job assignment (i.e., both $\mathbb{E}_{m} \pi_{N}\left(m, d ; a^{*}\right)$ and $\mathbb{E}_{m} \pi_{P}\left(m, d ; a^{*}\right)$ increase with $\left.d\right)$.

However, due to the signaling role of promotion, the market bids more often and more aggressively for a worker who is promoted than for a worker who is not. Hence, the marginal worker's value to the firm increases more with the breakup fee when he is promoted to job 2 than when he is kept in job 1 -i.e., $\mathbb{E}_{m} \pi_{P}$ increases more than $\mathbb{E}_{m} \pi_{N}$ as $d$ increases. In other words, a breakup fee protects the firm from labor-market competition irrespective of its job assignment decision, but this protection is more valuable when the worker is promoted, since a promoted worker is deemed to be of higher ability and receives higher wage offers. Consequently, the larger is the breakup fee, the stronger the firm's incentive to promote a worker.

But $d$ affects the firm's payoff (from the marginal worker) only when the market bid exceeds $d$; otherwise, it gets renegotiated down with certainty. Thus, when $d$ is sufficiently large such that under no scenario can the market bid more than $d$, it no longer affects the firm's payoff, and hence its promotion policy $a^{*}(d)$ no longer varies with $d$, either.

Another implication of Proposition 1 is that, in the absence of any breakup fee, job assignment remains inefficient, as too few workers are promoted $\left(a^{*}(0)>a^{E}\right)$. This inefficiency is similar to the one discussed in Waldman (1984), and it stems from the signaling role of job assignment that Waldman highlights. As a promoted worker is more likely to be of higher ability, the market bids more aggressively for a promoted worker. Hence, it is costlier to retain a promoted worker vis-à-vis a worker who has not been promoted. As the firm's expected profit from promoting the worker decreases, in equilibrium, a worker is promoted only if he is significantly more productive in job 2 than in job 1 so that the resulting productivity gains can offset the wage premium that the firm must offer to a promoted worker. But as discussed above, the firm can mitigate such inefficiencies by stipulating a breakup fee in the worker's contract ( $a^{*}$ decreases in $d$ ), since this serves as a commitment device that allows the firm to implement a more lenient promotion rule ex-post.

We conclude this section with the following two remarks. First, it can be argued that in the absence of any firm-specific matching gains (i.e., if $m<0$ with certainty), in our model the possibility of counteroffer can remedy inefficiencies in job assignment, since external recruiters would refrain from bidding due to the winner's curse problem discussed above (Golan, 2005). However, a distortion in job assignment à la Waldman (1984) would arise whenever the signaling role of promotion leads to a wage premium for the promoted worker (Waldman and Zax, 2016; also see DeVaro and Waldman, 2012). In our setting, the possibility that the worker could be a better match with an external recruiter (i.e., $m>0$ ) gives rise to such a wage premium. Even though the counteroffer dampens the external recruiters' bid by creating a winners' curse problem, when $m>0$ it is still profitable for external recruiters to bid for the worker, and they will bid more aggressively for a promoted worker, as promotion signifies higher ability.

Second, even though the use of a breakup fee may lessen inefficiencies in job assignment (as $a^{*}$ decreases in $d$ ), stipulating an arbitrarily large fee need not be optimal, even with the possibility of renegotiation. A sufficiently large breakup fee may lead to inefficient job assignment by inducing the firm to promote "too many" workers. For example, when $d>\psi_{1}$ we have $a^{*}<a^{E}$, i.e., more workers are promoted relative to the case where there are no information asymmetries (or no external recruiters). More importantly, even if the firm 
chooses a relatively small breakup fee (e.g., $d \leq \psi_{1}$ ), any such fee would accentuate inefficiencies in turnover through its influence on the external recruiters' bids. As the following sections elaborate, the optimal breakup fee trades off these two inefficiencies.

\section{The NATURE OF ALLOCATIVE INEFFiCIENCIES}

Before we characterize the optimal breakup fee, it is instructive to discuss the allocative inefficiencies associated with a given promotion cutoff, and how these inefficiencies may vary as the cutoff changes.

Consider an arbitrary promotion policy where the firm promotes the worker if and only if his ability $a \geq a_{0}$. Suppose that the cutoff $a_{0}>a^{E}$, as is the case with the equilibrium promotion policy in the absence of any breakup fee. Given this promotion policy, there are four sources of inefficiency in the allocation of the worker. We discuss them using Figure 2 (panel (i)) in which they correspond to the areas labeled as $A, B, C$ and $D$.

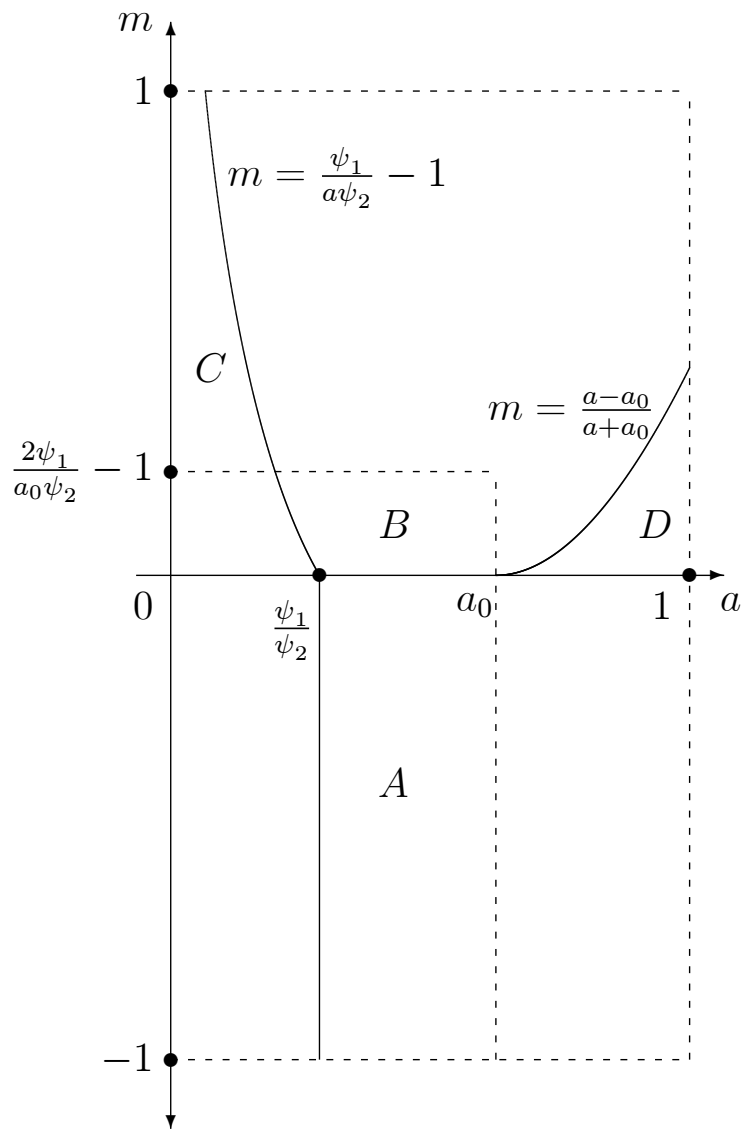

Panel $(i)$

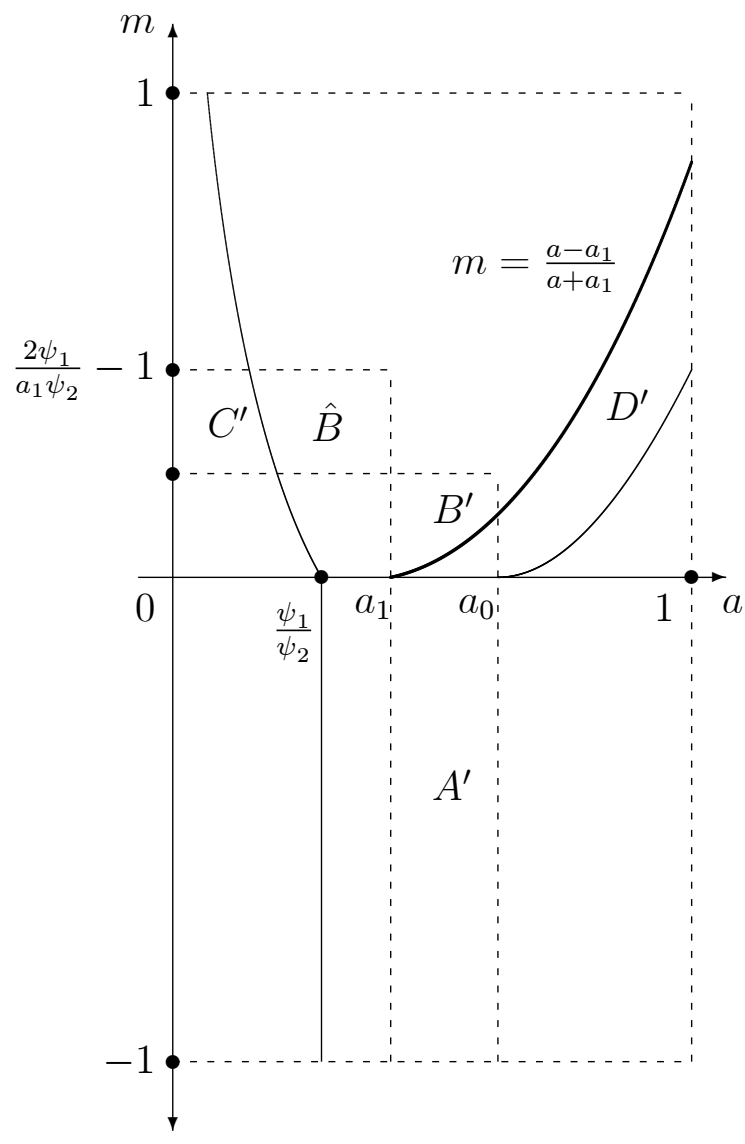

Panel (ii)

Figure 2. The allocative inefficiencies associated with

a given promotion policy.

When $m<0$ there is inefficiency in job assignment, as reflected by area $A$. The firm assigns a worker of ability $a \in\left[a^{E}, a_{0}\right]$ to job 1 even though he would be more productive in job 2 . When $m>0$, there are inefficiencies in both job assignment and turnover. There are two situations in which it would be efficient for the worker to leave the firm but he 
ends up staying (areas $B$ and $D$ ), and one situation in which it would be efficient for the worker to stay with the firm but he leaves (area $C$ ). More specifically, it is efficient for a worker of ability $a>\psi_{1} / \psi_{2}(1+m)$ to leave the firm. However, when $a<a_{0}$, the worker is not promoted and stays with the firm if $m \leq 2 \psi_{1} / a_{0} \psi_{2}-1$ (see equation (3)). Such misallocations are reflected by area $B$. Similarly, when $a \geq a_{0}$, the worker is promoted and retained whenever $\psi_{2} a \geq b_{P}^{*}$, or, equivalently, $m \leq\left(a-a_{0}\right) /\left(a+a_{0}\right)$ (see equation (5)). Area $D$ represents such misallocations. On the other hand, it is efficient for a worker to stay with the firm if his ability $a<\psi_{1} / \psi_{2}(1+m)$. However, such a worker is recruited by the external market whenever $m>2 \psi_{1} / a_{0} \psi_{2}-1$. Such misallocations are indicated by area $C$.

As mentioned earlier, the distortion captured by area $D$ stems from the winner's curse effect. External recruiters shade their bids as a successful bid sends a negative signal about the worker's ability, i.e., the initial employer did not find the worker productive enough to warrant a matching wage offer. Thus, for small $m$, the bid $b_{P}^{*}$ may be less than the worker's productivity with the firm in job 2 (i.e., $\psi_{2} a$ ) and the firm would find it profitable to match the bid, even though the worker would have been more productive with an external recruiter.

Consider now the marginal effects of changing the promotion threshold $\left(a_{0}\right)$ on these inefficiencies. Suppose that the threshold is lowered from $a_{0}$ to $a_{1}$ (see panel (ii)). Clearly, this change leads to a more efficient allocation of a worker with ability $a \in\left[a_{1}, a_{0}\right]$ : first, as the efficiency in job assignment would require, such a worker is now promoted to job 2 rather than kept in job 1; second, as turnover efficiency would require, such a worker would stay with the firm if $m<0$ (gains shown by area $A^{\prime}$ ) and leave for an external recruiter if $m>0$ (gains shown by area $B^{\prime}$ ).

But the improved allocation of these types of worker comes at the cost of distorted worker turnover. First, note that a promoted worker is now more likely to be retained by the firmeven if he is a better match with the recruiters - due to an aggravated winner's curse problem. As the promotion threshold is lowered, the expected productivity of a promoted worker decreases and so does the equilibrium bid. As a result, the firm retains a higher share of workers. Now a worker of ability $a$ is successfully recruited only if $m>\left(a-a_{1}\right) /\left(a+a_{1}\right)>$ $\left(a-a_{0}\right) /\left(a+a_{0}\right)$ (the increased turnover inefficiency is shown by area $\left.D^{\prime}\right)$.

Second, turnover is also reduced for the workers who are not promoted. As more workers are promoted, the expected quality of a worker who is kept in job 1 decreases. Hence, the worker leaves for an external recruiter only when the matching factor is sufficiently high, i.e., $m>2 \psi_{1} / a_{1} \psi_{2}-1>2 \psi_{1} / a_{0} \psi_{2}-1$. Such reduction in turnover has two opposite effects on the (expected) aggregate surplus. It reduces the surplus if the worker is of ability $a \in\left[\psi_{1} / \psi_{2}(1+m), a_{1}\right]$, as he would have been more productive with an external recruiter (loss shown by area $\hat{B}$ ); but it increases surplus otherwise, as such a worker is more productive with the firm and would have left for an external recruiter if the promotion threshold had been higher (gain shown by area $C^{\prime}$ ). However, since the matching factor cutoff, $2 \psi_{1} / a_{0} \psi_{2}-1$, is the one for which the worker has the same expected productivity with the firm (in job 1) and with the external recruiters (see equation (2)), these two effects (associated with areas $\hat{B}$ and $C^{\prime}$ ) exactly offset each other.

Therefore, the promotion policy that maximizes the (expected) aggregate surplus must balance the trade-off between improved worker-job matching (areas $A^{\prime}$ and $B^{\prime}$ ) and worsened worker-firm matching for promoted workers (area $D^{\prime}$ ). As we discuss below, this is also the trade-off that drives the firm's choice of an optimal breakup fee. 


\section{The optimal Breakup fee}

As external recruiters make zero profit due to competition, and the firm extracts all the rents from the worker by sufficiently lowering the first-period wage $\left(w_{1}\right)$, the firm appropriates the entire (expected) surplus that is generated by the coalition of the firm, the worker and the outside labor market. Consequently, the problem of choosing the optimal breakup fee can be conceived as the problem of choosing $d$ such that the equilibrium promotion rule $a^{*}(d)$ maximizes the aggregate surplus over the two periods. Thus, the firm's optimal contracting problem boils down to:

$$
\max _{d} \Pi(d):=\psi_{1}+S\left(a^{*}(d)\right)
$$

where $S\left(a_{0}\right)$ represents the expected aggregate surplus in period two under an arbitrary promotion threshold $a_{0}$, i.e.,

$$
\begin{aligned}
S\left(a_{0}\right) & :=\psi_{1} \operatorname{Pr}\left[\text { no turnover, no promotion } \mid a_{0}\right] \\
& +\mathbb{E}_{a, m}\left[\psi_{2} a \mid \text { no turnover, promotion, } a_{0}\right] \operatorname{Pr}\left[\text { no turnover, promotion } \mid a_{0}\right] \\
& +\mathbb{E}_{a, m}\left[\psi_{2} a(1+m) \mid \text { turnover, } a_{0}\right] \operatorname{Pr}\left[\text { turnover } \mid a_{0}\right] .
\end{aligned}
$$

The following proposition characterizes the optimal breakup fee.

Proposition 2. There exists a strictly positive cutoff $\underline{\psi}_{1}$ (given $\alpha$ and $\psi_{2}$ ) such that the optimal breakup fee is zero if $\psi_{1} \leq \psi_{1}$ but is strictly positive otherwise. Moreover, for $\psi_{1}>\underline{\psi}_{1}$, (i) the optimal breakup fee is increasing in $\psi_{1}$ and (ii) the use of breakup fee in the optimal contract enhances welfare as it increases the aggregate surplus.

Notice that the firm need not use any breakup fee if the worker's ability is public or if the promotion decision is private. In both cases promotion does not play any signaling role and hence there is no distortion in job assignments. Thus, a key implication of the above proposition is that breakup fees are more likely to be observed when the information on workers' ability is private (to the initial employer) but information on job assignments is public.

This prediction of the model is consistent with the recent surge in the use of non-compete clauses in employment contracts that could be conceived as contracts with steep breakup fees (Lobel, 2013). One may assume that the recent growth in the number and importance of recruiting networks (e.g., LinkedIn) has made a worker's career progress within a firm clearly visible to outsiders, while his actual quality is still his employer's private information. It is often argued that non-compete clauses are used to protect a firm's investment in human capital. But such an argument cannot explain Lobel's finding that non-compete clauses have proliferated even in industries where human-capital investment hardly plays a role.

Another salient implication of the above finding is that the optimality of a breakup fee is driven by the relative productivity of the worker in the two jobs: It is never optimal to stipulate a breakup fee if the worker's productivity in job 1 (i.e., $\psi_{1}$ ) is too low relative to his expected productivity in job 2 (as reflected by $\psi_{2}$ ). Otherwise, it is always optimal to specify a breakup fee in the employment contract, and the size of this fee increases as the difference between the worker's expected productivity in the two jobs gets smaller. In other 
words, breakup fees are more likely to be used when the production technologies in the preand post-promotion jobs are similar (e.g., they involve similar sets of tasks). ${ }^{11}$

The intuition behind this finding is as follows. As discussed above, the firm's promotion threshold $a^{*}(d)$ is decreasing in $d$. Also recall that such a reduction in promotion threshold leads to a trade-off between the gains from improved efficiency in job assignment and the loss from more inefficient turnover for the promoted workers. When $\psi_{1}$ is small, the marginal gain from the former effect is lower than the marginal loss from the latter. To see this, note that for low $\psi_{1}$, the equilibrium promotion rule $a^{*}$ is also low even in the absence of any breakup fee: As the worker is hardly productive in job 1, the firm has a strong incentive to assign him to job 2 . As most workers are promoted (when $\psi_{1}$ is small), the marginal worker who remains in job 1 is of relatively low ability and assigning him to job 2 (as efficiency in job assignment dictates) has only a small impact on his productivity. Thus, while the introduction of a breakup fee does improve job assignment, its marginal benefit is rather small. In contrast, its marginal cost stemming from inefficient turnover of promoted workers is still significant, as most types of worker are assigned to job 2 in the first place. Hence, when $\psi_{1}$ is small, the marginal benefit of a breakup fee (in terms of efficient promotion) is more than offset by its marginal cost (in terms of reduced turnover of the promoted workers), and it is optimal not to use such a fee in the employment contract.

But when $\psi_{1}$ is high, the opposite happens: The marginal benefit from efficiency in job assignment dominates the marginal cost of inefficiency in turnover. When $\psi_{1}$ is large, in the absence of any breakup fee very few types of worker are promoted in equilibrium. Thus, the marginal worker who misses promotion is of relatively high ability and the gains in productivity from (efficiently) promoting him are relatively large. In contrast, the loss from inefficiencies in turnover are small as very few types of worker are promoted in the absence of any breakup fees. Hence, when $\psi_{1}$ is large, the firm can increase its profit by stipulating a breakup fee that ensures a more efficient promotion policy.

Finally, consider the optimality of breakup fees from the social welfare perspective. Since the firm extracts the entire surplus generated by the worker, if the inclusion of a breakup fee is profit-enhancing for the firm, it is also socially optimal - it increases the aggregate social surplus generated by the coalition of the firm, the worker and the outside labor market.

\section{Discussion and extensions}

In this section, we highlight the implications of firm-specific human capital in our model and also explore the robustness of our key findings to a set of alternative modeling assumptions.

6.1. Firm-specific human capital. The key role of a breakup fee in our setting is to shield the firm from the competitive pressure on wages that results when the promotions are taken as signals of worker quality. In the process, breakup fees improve efficiency in job assignment, though at the cost of inefficiencies in turnover. But such competitive pressure on wages is less likely to arise when firm-specific human capital becomes more important

\footnotetext{
${ }^{11}$ Unfortunately, empirical findings on this issue are rather scant as task variations across jobs in the organizational hierarchies may be difficult to measure. An empirical test of our prediction can potentially follow the approach suggested in DeVaro et al. (forthcoming). In an analysis of discrimination in labor markets, they construct a measure of task variability from information on factors such as knowledge required, supervision received, guidelines, etc., that describe the nature of a given job within the organizational hierarchy of a given firm.
} 
in driving worker productivity. Indeed, the canonical models on the signaling role of job assignment (Waldman, 1984; Ghosh and Waldman, 2010) suggest that inefficiency in job assignment becomes smaller as firm-specific human capital becomes more important. Thus, one may conjecture that breakup fees are less likely to be used when firm-specific human capital is more critical for the production process.

In our model, one may interpret $\alpha$ as a measure of the importance of firm-specific human capital. Recall that the larger $\alpha$ is, the less likely it is that the worker will be a better match with an external recruiter. Unfortunately, an analytical derivation of the comparative statics of the optimal breakup fee $\left(d^{*}\right)$ with respect to $\alpha$ appears to be algebraically intractable. Nevertheless, as the following proposition indicates, the impact of firm-specific human capital is more nuanced than what the above conjecture suggests.

Proposition 3. (i) The promotion cutoff $a^{*}(d)$ decreases with $\alpha$ when $d<\psi_{1}$ and increases with $\alpha$ otherwise. (ii) The threshold $\underline{\psi}_{1}$ (i.e., the value of $\psi_{1}$ above which it is optimal to specify a breakup fee) is decreasing in $\bar{\alpha}$.

This proposition has two important implications. First, promotion incentives increase as firm-specific human capital becomes more important, provided that the breakup fee is not too high. When $d<\psi_{1}$, the argument behind this finding is exactly the same as the one discussed above. As the market is less likely to compete for the worker, the upward pressure on wages following promotion is weaker, and hence, the firm is more likely to promote a worker.

But when the breakup fee is sufficiently large $\left(d>\psi_{1}\right)$, the firm is better off if the marginal worker (the one with ability $a^{*}(d)$ ) leaves, regardless of whether he is promoted or not. (Notice that in this case the breakup fee exceeds the worker's productivity in both jobs, i.e., $d>\psi_{1}>\psi_{2} a^{*}(d)$.) In such a scenario, the firm benefits from promoting the worker, as this increases the probability of an external offer. However, this benefit becomes weaker as $\alpha$ increases: Since the worker is more likely to be a better match with the firm, external recruiters are less likely to bid for him. Therefore, the firm's incentive for promoting the worker decreases with $\alpha$.

Second, the aforementioned conjecture about the negative relationship between the use of breakup fees and the importance of firm-specific human capital need not hold. In our setting, as firm-specific human capital becomes more important, the firm is more likely to stipulate a breakup fee. As firm-specific human capital becomes more critical (i.e., $\alpha$ increases), there are two opposite effects on the optimal breakup fee.

As discussed earlier, firm-specific human capital dampens the competitive pressure on wages and incentivizes the firm to promote more workers, i.e., $a^{*}(0)$ decreases with $\alpha$. Clearly, this effect reduces the need for a breakup fee in the optimal contract when the firm tries to implement a specific promotion cutoff. But there is a countervailing effect. When $\alpha$ increases, this lowers the promotion cutoff that maximizes the (expected) aggregate surplus. As the worker is likely to be more productive within the firm, turnover is less likely to be efficient in the first place. So, if the promotion threshold is lowered (when $\alpha$ remains high), the associated marginal loss from an inefficient turnover is small, whereas the marginal gain from a more efficient job-assignment is large: Since the worker is now more likely to stay with the firm, assigning him to the right job becomes more important. Thus, even 
though $a^{*}(0)$ decreases with $\alpha$, the firm may now want to implement an even lower cutoff for promotion, and use a breakup fee to accomplish this.

However, it is important to note that the argument above hinges critically on the fact that external recruiters can hire a worker even if he is not promoted. The result is overturned if one assumes that recruiters bid for a worker only if he is promoted while a worker who remains in job 1 is insulated from the outside labor market. ${ }^{12}$ In such a setting, the firm is indeed less likely to use a breakup fee when $\alpha$ increases as the countervailing effect mentioned above is weaker. The working-paper version of this article (Mukherjee and Vasconcelos, 2015) presents a complete analysis of this setting.

To sum up, the relationship between the use of breakup fees and the importance of firmspecific human capital is more subtle than what the extant literature suggests; the market visibility of workers who remain in lower-level jobs plays a key role in governing this relationship.

6.2. On the nature of the external labor market. Our model makes two major assumptions about the external labor market. (i) The external recruiters can only offer job 2, whereas the initial employer can offer both jobs in both periods. (ii) A competitive external labor market is available only in period two, while the period-one employer is a monopsonist, as it is the only firm that can offer the entry-level job. While these assumptions simplify the analysis and exposition, it is important to note that the key economic effects that our model illustrates do not hinge on either one of them.

It is straightforward to amend the model and allow the external recruiters to offer job 1. In fact, our model is identical to a setting in which the worker's output in period one (in job 1) with the initial employer is 0 , but in period two, his productivity in job 1 with the initial employer is $\psi_{1}$ whereas with an external recruiter it would remain at 0 . In other words, there is a firm-specific human capital accumulation in job 1 that makes the worker more productive if he continues with the initial employer. Therefore, even if the external recruiters can offer job 1, it is never worthwhile for them to recruit a worker for this job, and the subsequent analysis of the optimal breakup fee becomes identical to that in our initial setup.

One may also consider an alternative setup that closely parallels our initial modeling specification. Suppose that the external recruiters can offer both jobs, and that the worker's productivity in both jobs is affected by firm-specific match factors. In particular, assume that the worker produces $\psi_{1}$ in period one (in job 1 ) with the initial employer. But in period two, the external recruiters can hire him either for job 1 or for job 2 . In jobs 1 and 2 he produces $\psi_{1}\left(1+m_{1}\right)$ and $\psi_{2} a\left(1+m_{2}\right)$, respectively, where $m_{1}$ and $m_{2}$ are (stochastic) firm-specific matching gains and $m_{1} \neq m_{2}$. One can show that even in such a setup, the signaling role of promotion makes promotion expensive and too few workers are promoted, i.e., in the absence of any breakup fees, job assignment remains inefficient. Moreover, so long as the breakup fee is not too large (i.e., $d<\psi_{1}$ ), the promotion threshold decreases in the breakup fee. ${ }^{13}$ In other words, the key trade-off with breakup fees that we highlight in our model persists.

\footnotetext{
${ }^{12}$ Such an environment is reminiscent of Milgrom and Oster (1987). In our setting, one can justify such behavior by the the recruiters by assuming that if a worker with sufficiently low ability is placed in job 2 , he may cause significant damage to the firm's value. As the external recruiters never observe the worker's ability, in equilibrium, they never bid for a worker who has been retained in job 1 .

${ }^{13}$ We omit the formal derivation of this result as it closely parallels our initial analysis.
} 
If one assumes that the external recruiters can offer job 1, it is also natural to assume that there might be competition for the worker even in period one. How would the optimal contract change in such a setting? Notice that, as discussed in Section 5, the optimal fee $d^{*}$ is chosen so as to maximize the aggregate surplus generated by the coalition of the firm, the worker and the outside labor market, and the firm extracts the entire surplus upfront by lowering the first-period wage $w_{1}$. If we assume that there is competition for the worker in period one, the worker retains all bargaining power in period one. Hence, the optimal contract would have the same breakup fee $d^{*}$, but the firm would raise the worker's periodone wage $w_{1}$ so as to transfer the entire surplus to him. In other words, the use of a breakup fee could be conceived as a competitive response by the firms to the inefficiencies in job assignment, à la Waldman (1984).

6.3. Renegotiation of breakup fee. Our model allows the firm to renegotiate the breakup fee $(d)$ down whenever it is profitable for the firm to do so. It turns out that our key results continue to hold even if we assume that the breakup fee is not renegotiable. However, in such an environment, breakup fees lead to a new effect: Such fees may aggravate inefficiencies in turnover by directly foreclosing external recruiters from bidding for the worker. A detailed analysis of this case is available in Mukherjee and Vasconcelos (2015), but it is relatively straightforward to see why the foreclosure effect may occur. When the breakup fee is not renegotiable, an external recruiter successfully bids away the worker only if his bid exceeds the fee. Therefore, when the fee is sufficiently large (in particular, if $d>\psi_{1}$ ), the external recruiter may refrain from bidding even if the worker would be more productive with the external recruiter.

As this effect occurs only when the fee is sufficiently large, it does not affect our findings on when such a fee should be used. When $d=0$, the effects of raising $d$ on the margin are still driven by the same trade-off between efficiencies in job-assignment and turnover that we have discussed earlier. Hence, Proposition 2 remains largely unaffected: A breakup fee is optimal only when $\psi_{1}$ is sufficiently large, and in this case the use of a breakup fee is also welfare-enhancing. Similarly, the characterization of the equilibrium promotion threshold, as given in Proposition 1 (i.e., $a^{*}(d)$ decreases with $d$ ), continues to hold so long as $d$ is not too large. However, if $d$ is sufficiently large, $a^{*}(d)$ starts to increase with $d$. When the fee is sufficiently large and cannot be renegotiated down, it may be more profitable for the firm to let the worker leave than to retain him. So the firm may find it optimal to be more selective in its promotion policy: As promotion becomes a stronger signal of ability, it elicits more aggressive bidding from external recruiters and raises the likelihood of turnover. Of course, when $d$ becomes even larger, external recruiters are completely foreclosed and the promotion policy is no longer affected by $d$.

It is interesting to note that the discussion above is reminiscent of the model of bilateral trade with potential entrants à la Aghion and Bolton (1987) in which the seller may stipulate a breakup fee in his contract offer to the buyer in order to foreclose a more efficient firm from entering the market. However, as is the case in our model, such a foreclosure effect disappears if the buyer and the seller can renegotiate the breakup fee up on entry (Spier and Whinston, 1995). ${ }^{14}$

\footnotetext{
${ }^{14}$ Spier and Whinston (1995) also note that even with renegotiation, the market foreclosure effect reappears if the seller needs to make relationship-specific investments and the entrant has some market power. In the context of our model, this finding suggests that if the initial employer invests in its worker for firm-specific human capital accumulation and if recruiters can make take-it-or-leave-it offers, then contract renegotiation
} 
6.4. Breakup fee based on ability. In some settings the firm may determine the breakup fee after observing the worker's ability. That is, the firm may simultaneously decide on the promotion of the worker and on the breakup fee. How would the optimal contract change in such a setting? While a complete characterization of the equilibrium appears intractable, two salient observations can be made. First, in equilibrium, the breakup fee may vary with ability, and hence the optimal contract also serves as a signal (in addition to the signal implied by job assignment) of the worker's quality. ${ }^{15}$ Second, the breakup fee may always be used - the worker's relative productivity in the two jobs no longer affects the optimality of breakup fees. The latter observation is somewhat nontrivial and the argument is as follows.

Note that in our baseline model, the issues of allocational efficiencies and surplus extraction can be decoupled: Surplus extraction is done using the period 1 wage $w_{1}$ and $d$ is chosen so as to implement the promotion policy that maximizes the aggregate surplus. When the difference in a worker's productivity between jobs is high, the gain in worker-job allocation from using $d$ does not compensate the loss in worker-firm allocation, and the firm optimally sets $d=0$. But if $d$ is specified along with the promotion decision at the end of period 1 , the choice of $d$ also affects surplus extraction. So long as there is a chance that a worker may receive an offer from external recruiters, it will be optimal to use a break up fee: With a breakup fee, it is always cheaper to retain a worker, and the firm receives a compensation in case the worker leaves. This argument holds even if the difference between the worker's productivity in the two jobs is large. So, in this case, $d$ is used more as a tool to appropriate surplus than as a tool to achieve allocational efficiency. Of course, even in this case, the use of $d$ still has the trade-off we highlight earlier: It leads to more efficient promotion but compromises turnover efficiencies. But this trade-off never precludes the use of breakup fees in the optimal contract.

6.5. Severance payments and long-term wage contracts. Our analysis assumes that long-term wage contracts are infeasible and wages in period two are set in the spot market. While this is a common assumption in the literature (see, for example, Zabojnik and Bernhardt, 2001; DeVaro and Waldman, 2012), it is interesting to note the implications of long-term contracts in our setting. Instead of relying on breakup fees, the firm can use longterm contracts that commit to severance pay or to period-two wages to alleviate inefficiencies in job assignment.

Consider the use of severance pay: The firm commits to make a lump-sum payment to the worker when the employment relationship terminates, irrespective of whether termination occurs at the end of period one or during period two. Suppose that severance pay can depend on the job assignment. The firm can always implement the promotion rule that maximizes aggregate surplus $S\left(a^{*}\right)$ by choosing the payments appropriately to mitigate the wage differential between jobs that stems from the job-assignment signal. As in our model, the optimal promotion rule trades off efficiencies in job-assignment and turnover and, in equilibrium, both inefficiencies persist. Also, in equilibrium, severance pay is larger in job 1 compared with job 2 , as it must generate a stronger incentive for the firm to promote the worker.

However, such a contract is profitable provided that the firm can ex-ante recover the severance payment by lowering the period-one wage of the worker. As these payments are

need not rule out the possibility of market foreclosure. A complete analysis of this issue is beyond the scope of this article and remains an interesting topic for future research.

${ }^{15}$ A similar issue is highlighted in Bernhardt and Scoones (1993). 
made to all workers irrespective of their ability and job assignment, this would require the firm to significantly lower the worker's period-one wage to extract all rents. So, if the worker has liquidity constraints, such a low period-one wage may not be feasible and the optimal contract may still fall short of achieving the promotion cutoff that maximizes the aggregate surplus $S\left(a_{0}\right) \cdot{ }^{16}$

The implications of the long-term wage contracts are also similar. Waldman (1984) shows that long-term wage contracts that commit to period-two wages of the worker (along with the period-one wage) can ensure efficient job-assignment by making the period-two wage contingent on the job assignment. As one would expect, the same holds in our setting as well, even though, in equilibrium, job assignment may remain inefficient as it trades off efficiency in turnover. As in the case of severance payments, such a contract improves efficiency in job assignment by making it more costly for the firm to keep a worker in job 1: The firm implements the promotion rule that maximizes the aggregate surplus $S\left(a_{0}\right)$ by committing to a period-two wage that is larger when the worker stays in job 1 than when he is assigned to job 2.

It is important to note, however, that the use of such long-term wage contracts is seldom observed in practice, as the firm may lack the necessary commitment power. Also, the key feature of the optimal contract mentioned above -i.e., committing a higher wage to workers who fail to get promoted - is rather unrealistic. As promotion tournaments are often used to provide work incentives, such a wage schedule may undermine the incentive role of promotions. Also, similarly to the case of severance payments, if the workers are liquidity constrained, such a contract may not be feasible and the optimal contract may fail to ensure efficient promotion.

\section{Conclusion}

Breakup fees are contracting tools that firms frequently use to restrict turnover. Several authors have argued that such a restriction could be beneficial to the firm as it increases the firm's incentives for investment in its workers' human capital, guards against diffusion of proprietary knowledge, and protects the firm from potential losses associated with employee spinoffs. This article highlights a novel trade-off associated with the use of such fees in an environment with asymmetric learning about worker's productivity and firm-specific matching gains. The use of breakup fees reduces inefficiencies in job-assignment that stems from its signaling value (à la Waldman, 1984), but their use also creates inefficiencies in turnover.

Our key finding is that the optimality of the breakup fee depends on the relative size of the worker's expected productivity across jobs. If there are substantial (expected) productivity gains from promotion, then it is never optimal to specify any breakup fee in the employment contract. Moreover, when the use of a breakup fee is optimal for the firm, it is also socially optimal as it increases the aggregate social welfare. In addition, our analysis suggests a subtle link between the optimality of breakup fees and the importance of firm-specific human capital, as it critically depends on the market visibility of workers at different levels of the organizational hierarchy.

Notice that any personnel decision of the firm, including but not limited to job assignment, that releases information on workers' quality to the outside labor market makes the firm

\footnotetext{
${ }^{16}$ Liquidity constraints can be less binding under contracts with breakup fees as the worker may have lower rents in period two (hence the period-one wage may not have to be lowered as much to ensure complete rent extraction).
} 
vulnerable to raids. This leads to higher wages for retained workers, and the threat of such competition distorts the firm's personnel decisions in the first place. ${ }^{17}$ Thus, the benefit of breakup fees that we highlight here is not limited to improving the efficiency in job assignments, per se. Such fees may be used to mitigate inefficiencies in any personnel decision that may be distorted due to its signaling role in the outside labor market.

There are several other economic effects that are interesting and relevant in our environment, though they are beyond the scope of our model. One may assume that to be productive in the "post-promotion" job, it is necessary for the worker (and/or the firm) to invest in human capital. How would the presence of breakup fees affect the incentives for investment? The answer to this question depends on whether the human capital is general or firm-specific and who undertakes the investment. ${ }^{18}$ It would also be interesting to consider the case in which the market could screen promoted workers (see Ricart i Costa (1988) for a related model on managerial job assignment). In such a scenario, the firm's promotion policy continues to play an important role, as it affects the worker's information rent associated with the screening contract that the market may offer (and such rents, in turn, can be extracted by the initial employer). Finally, if there is a moral hazard problem in the production process, the use of breakup fees may create an additional cost: this mutes work incentives by dampening external recruiters' bids and thereby lowering the prospect of future wage increments (see Kräkel and Sliwka (2009) for a similar discussion).

The issues raised above offer useful directions for future research and may offer additional insights into firms' job assignment policies. However, the key trade-off between the job assignment and turnover that we highlight in this article continues to play a critical role in all these settings and we expect that our findings will be informative in analyzing such complex environments.

\section{APPENDIX}

This appendix contains the proofs omitted in the text.

Proof of Proposition 1. To simplify the exposition, let $\Pi_{N}\left(d ; a^{*}\right):=\mathbb{E}_{m} \pi_{N}\left(m, d ; a^{*}\right)$ and $\Pi_{P}\left(d ; a^{*}\right):=\mathbb{E}_{m} \pi_{P}\left(m, d ; a^{*}\right)$. Using (3) and (4), we obtain that:

$$
\Pi_{N}\left(d ; a^{*}\right)=\left\{\begin{array}{cc}
\psi_{1} G\left(\frac{2 \psi_{1}}{\psi_{2} a^{*}}-1\right)+d\left[1-G\left(\frac{2 \psi_{1}}{\psi_{2} a^{*}}-1\right)\right] & \text { if } d \leq \psi_{1} \\
\psi_{1} G\left(\frac{2 \psi_{1}}{\psi_{2} a^{*}}-1\right)+\int_{\frac{2 \psi_{1}}{\psi_{2} a^{*}}-1}^{\frac{2 d}{\psi_{2} a^{*}}-1} \frac{1}{2} \psi_{2} a^{*}(1+m) d G(m) & \\
+d\left[1-G\left(\frac{2 d}{\psi_{2} a^{*}}-1\right)\right] & \text { if } d>\psi_{1}
\end{array}\right.
$$

and using (5) and (6), we obtain that

\footnotetext{
${ }^{17}$ For example, Loveman and O'Connell (1996) offer a case study on an IT firm where the firm must decide whether to send its software programmers to the clients'premises or to require them to work in-house (and ship out the final product to the client). The firm experiences a high rate of turnover among the workers who are sent to the clients'sites as the client firms learn more about the quality of the workers and bid away the better ones. The turnover risk distorts the firm's job design policy as it becomes biased towards in-house projects.

${ }^{18}$ Golan (2005) addresses these issues in a related environment but does not consider breakup fees or matching gains with the outside labor market. Also see Bernhardt and Scoones (1998) for a related discussion on the incentives to invest on human capital.
} 


$$
\Pi_{P}\left(d ; a^{*}\right)=\left\{\begin{array}{cc}
\psi_{2} a^{*} G(0)+d[1-G(0)] & \text { if } d \leq \psi_{2} a^{*} \\
\psi_{2} a^{*} G(0)+\int_{0}^{\frac{d-\psi_{2} a_{2} a^{*}}{d+\psi^{*}}} \psi_{2} a^{*} \frac{1+m}{1-m} d G(m) & \\
+d\left[1-G\left(\frac{d-\psi_{2} a^{*}}{d+\psi_{2} a^{*}}\right)\right] & \text { if } \psi_{2} a^{*}<d \leq \psi_{2} \\
\psi_{2} a^{*} G(0)+\int_{0}^{\frac{1-a^{*}}{1+a^{*}}} \psi_{2} a^{*} \frac{1+m}{1-m} d G(m)+ & \\
\int_{\frac{1-a^{*}}{1+a^{*}}}^{\frac{2 d}{\psi_{2}\left(1+a^{*}\right)}-1} \frac{a^{*}+1}{2} \psi_{2}(1+m) d G(m)+ & \\
+d\left[1-G\left(\frac{2 d}{\psi_{2}\left(a^{*}+1\right)}-1\right)\right] & \text { if } d>\psi_{2} .
\end{array}\right.
$$

The remainder of the proof is given in three steps, each characterizing the equilibrium promotion rule for a given range of values of the breakup fee $d$.

Step 1: Equilibrium promotion rule when $d \leq \psi_{1}$. In this case, $\Pi_{N}\left(d ; a^{*}\right)=\psi_{1}$ for all $a^{*} \leq \psi_{1} / \psi_{2}$ (since $2 \psi_{1} / \psi_{2} a^{*}-1>1$ and $\left.G\left(2 \psi_{1} /\left(\psi_{2} a^{*}\right)-1\right)=1\right)$, and $\Pi_{N}\left(d ; a^{*}\right)$ decreases with $a^{*}$ for $a^{*}>\psi_{1} / \psi_{2}$. Hence, $\Pi_{N}\left(d ; a^{*}\right)$ is non-increasing in $a^{*}$. In contrast, $\Pi_{P}\left(d ; a^{*}\right)$ is increasing in $a^{*} \in[0,1]$ : clearly, $\Pi_{P}\left(d ; a^{*}\right)$ increases with $a^{*}$ when $d \leq \psi_{2} a^{*}$; and when $\psi_{2} a^{*}<d$

$$
\frac{\partial}{\partial a^{*}} \Pi_{P}\left(d ; a^{*}\right)=\psi_{2} G(0)+\int_{0}^{\frac{d-\psi_{2} a^{*}}{d+\psi_{2} a^{*}}} \psi_{2} \frac{1+m}{1-m} d G(m)>0
$$

Thus, given $d$, the equation $\Pi_{N}\left(d ; a^{*}\right)=\Pi_{P}\left(d ; a^{*}\right)$, which defines $a^{*}(d)$, has at most one solution. To see that it has a solution, and that such solution $a^{*}(d) \in\left[\psi_{1} / \psi_{2}, 1\right)$, observe that $\Pi_{N}$ and $\Pi_{P}$ are continuous in $a^{*}$,

$$
\Pi_{P}\left(d ; \frac{\psi_{1}}{\psi_{2}}\right)=\psi_{1} G(0)+d[1-G(0)] \leq \psi_{1}=\Pi_{N}\left(d ; \frac{\psi_{1}}{\psi_{2}}\right)
$$

and

$$
\begin{aligned}
\Pi_{P}(d ; 1) & =\psi_{2} G(0)+d[1-G(0)] \\
& \geq \psi_{1} G\left(\frac{2 \psi_{1}}{\psi_{2}}-1\right)+d\left[1-G\left(\frac{2 \psi_{1}}{\psi_{2}}-1\right)\right]=\Pi_{N}(d ; 1),
\end{aligned}
$$

where this inequality follows from Assumption 1, the fact that $\psi_{1}<\psi_{2}$ (which is implied by Assumption 1), and $d \leq \psi_{1}$.

We next show that $a^{*}(d)$ decreases with $d$. Since $\Pi_{P}$ increases with $a^{*}$ and $\Pi_{N}$ decreases with $a^{*}$, it is sufficient to show that $\partial \Pi_{P} / \partial d>\partial \Pi_{N} / \partial d$ when $a^{*}=a^{*}(d)$. Observe that

$$
\frac{\partial \Pi_{P}}{\partial d}-\frac{\partial \Pi_{N}}{\partial d}=G\left(\frac{2 \psi_{1}}{\psi_{2} a^{*}}-1\right)-G(0) .
$$

This is always positive when $a^{*}=a^{*}(d)$, since $a^{*}(d)<2 \psi_{1} / \psi_{2}$. To see that $a^{*}(d)<2 \psi_{1} / \psi_{2}$, note that

$$
\Pi_{P}\left(d ; \frac{2 \psi_{1}}{\psi_{2}}\right)=2 \psi_{1} G(0)+d[1-G(0)]>\psi_{1} G(0)+d[1-G(0)]=\Pi_{N}\left(d ; \frac{2 \psi_{1}}{\psi_{2}}\right)
$$

and recall that $\Pi_{P}$ increases with $a^{*}$ while $\Pi_{N}$ decreases with $a^{*}$. 
Finally, we obtain $a^{*}\left(\psi_{1}\right)=\psi_{1} / \psi_{2}$ as $\Pi_{P}\left(\psi_{1} ; \psi_{1} / \psi_{2}\right)=\Pi_{N}\left(\psi_{1} ; \psi_{1} / \psi_{2}\right)=\psi_{1}$. And $a^{*}(0)>$ $\psi_{1} / \psi_{2}$ as $a^{*}\left(\psi_{1}\right)=\psi_{1} / \psi_{2}$ and $a^{*}(d)$ decreases in $d$.

Step 2: Equilibrium promotion rule when $\psi_{1}<d \leq \psi_{2}$. As before, $\Pi_{N}\left(d ; a^{*}\right)=\psi_{1}$ for all $a^{*} \leq \psi_{1} / \psi_{2}$. Observe that $\Pi_{P}\left(d ; a^{*}\right)$ is continuous and increasing in $a^{*}, \Pi_{P}(d ; 0)=0$, and

$$
\begin{aligned}
\Pi_{P}\left(d ; \frac{\psi_{1}}{\psi_{2}}\right) & =\psi_{1} G(0)+\int_{0}^{\frac{d-\psi_{1}}{d+\psi_{1}}} \psi_{1} \frac{1+m}{1-m} d G(m)+d\left[1-G\left(\frac{d-\psi_{1}}{d+\psi_{1}}\right)\right] \\
& >\psi_{1} G(0)+\psi_{1} \int_{0}^{\frac{d-\psi_{1}}{d+\psi_{1}}} d G(m)+\psi_{1}\left[1-G\left(\frac{d-\psi_{1}}{d+\psi_{1}}\right)\right]=\psi_{1},
\end{aligned}
$$

where the inequality follows from the fact that $(1+m) /(1-m)>1$ and $d>\psi_{1}$. Thus, given $d$, the equation $\Pi_{N}\left(d ; a^{*}\right)=\Pi_{P}\left(d ; a^{*}\right)$ has a unique solution in the interval $\left(0, \psi_{1} / \psi_{2}\right)$. We next show it has no solution in $\left[\psi_{1} / \psi_{2}, 1\right]$ by showing that $\partial \Pi_{P} / \partial a^{*}>\partial \Pi_{N} / \partial a^{*}$ for all $a^{*}>\psi_{1} / \psi_{2}$ when $d \in\left(\psi_{1}, \psi_{2}\right]$. Regardless of the value of $d$,

$$
\frac{\partial}{\partial a^{*}} \Pi_{P}\left(d ; a^{*}\right) \geq \psi_{2} G(0)=\alpha \psi_{2} .
$$

Also, for $d>\psi_{1}$,

$$
\begin{aligned}
\frac{\partial}{\partial a^{*}} \Pi_{N}\left(d ; a^{*}\right) & =\int_{\frac{2 \psi_{1}}{\psi_{2} a^{*}}-1}^{\frac{2 d}{\psi_{2} a^{*}}-1} \frac{1}{2} \psi_{2}(1+m) d G(m) \leq \frac{1}{2} \alpha \psi_{2} \int_{\frac{2 \psi_{1}}{\psi_{2} a^{*}}-1}^{\left.\max \frac{2 d}{\psi_{2} a^{*}}-1,1\right\}}(1+m) d m \\
& \leq \frac{1}{2} \alpha \psi_{2} \int_{\frac{2 \psi_{1}}{\psi_{2} a^{*}}-1}^{1}(1+m) d m \leq \alpha \psi_{2}
\end{aligned}
$$

for all $a^{*}>\psi_{1} / \psi_{2}$. Thus, when $d \in\left(\psi_{1}, \psi_{2}\right], a^{*}(d)$ is unique and $a^{*}(d)<\psi_{1} / \psi_{2}$. Finally, because $(i) \Pi_{N}\left(d ; a^{*}\right)=\psi_{1}$ for all $a^{*} \leq \psi_{1} / \psi_{2},(i i) \Pi_{P}\left(d ; a^{*}\right)$ is increasing in $a^{*}$ and (iii)

$$
\frac{\partial}{\partial d} \Pi_{P}\left(d ; a^{*}\right)=1-G\left(\frac{d-\psi_{2} a^{*}}{d+\psi_{2} a^{*}}\right)>0
$$

when $d>\psi_{1}$ and $\psi_{2} a^{*} \leq d$, we obtain that $a^{*}(d)$ is decreasing in $a^{*}(d)$.

Step 3: Equilibrium promotion rule when $d>\psi_{2}$. The analysis of this case follows closely the analysis in the previous step. Once again, $\Pi_{N}\left(d ; a^{*}\right)=\psi_{1}$ for all $a^{*} \leq \psi_{1} / \psi_{2}$. Moreover, $\Pi_{P}\left(d ; a^{*}\right)$ is continuous and increasing in $a^{*}$ and $\Pi_{P}(d ; 0)=0$. Now, observe that $\Pi_{P}$ is nondecreasing in $d$, which jointly with (13) in Step 2 implies that $\Pi_{P}\left(d ; \psi_{1} / \psi_{2}\right)>\psi_{1}$. Hence, given $d, \Pi_{N}\left(d ; a^{*}\right)=\Pi_{P}\left(d ; a^{*}\right)$ has a unique solution in the interval $\left(0, \psi_{1} / \psi_{2}\right)$. We next show it has no solution in $\left[\psi_{1} / \psi_{2}, 1\right]$. It suffices to show that $\partial \Pi_{P} / \partial a^{*}>\partial \Pi_{N} / \partial a^{*}$ for all $a^{*}>\psi_{1} / \psi_{2}$ when $d>\psi_{2}$. Clearly, (14) holds when $d>\psi_{2}$ and, therefore, $\partial \Pi_{N} / \partial a^{*} \leq \alpha \psi_{2}$ for all $a^{*}>\psi_{1} / \psi_{2}$. Next, observe that when $d>\psi_{2}$,

$$
\begin{aligned}
\frac{\partial}{\partial a^{*}} \Pi_{P}\left(d ; a^{*}\right) & =\psi_{2} G(0)+\int_{0}^{\frac{1-a^{*}}{1+a^{*}}} \psi_{2} \frac{1+m}{1-m} d G(m)+\int_{\frac{1-a^{*}}{1+a^{*}}}^{\frac{2 d}{\psi_{2}\left(1+a^{*}\right)}-1} \frac{1}{2} \psi_{2}(1+m) d G(m) \\
& >\psi_{2} G(0)=\alpha \psi_{2} .
\end{aligned}
$$

Thus, for each $d>\psi_{2}$, the promotion cut-off $a^{*}(d)$ is unique and satisfies $a^{*}(d) \leq a^{*}\left(\psi_{2}\right)<$ $\psi_{1} / \psi_{2}$. The remaining question is whether $a^{*}(d)$ decreases with $d$. When $d>\psi_{2}$,

$$
\frac{\partial}{\partial d} \Pi_{P}\left(d ; a^{*}\right)=1-G\left(\frac{2 d}{\psi_{2}\left(a^{*}+1\right)}-1\right) .
$$


Therefore, $\partial \Pi_{P}\left(d ; a^{*}\right) / \partial d>0$ if and only if

$$
\frac{2 d}{\psi_{2}\left(a^{*}+1\right)}-1<1 \text { or, equivalently, if } d<\psi_{2}\left(a^{*}+1\right) .
$$

Observe first that when $d=\psi_{2}$ this condition is satisfied for all $a^{*}$. Therefore, $a^{*}(d)$ decreases with $d$, at $d=\psi_{2}$. When $d=\psi_{2}+\psi_{1}$, this condition requires that $a^{*}>\psi_{1} / \psi_{2}$. Since $\left(\psi_{2}+\psi_{1}\right) a^{*}<\psi_{1} / \psi_{2}$, we obtain that $a^{*}(d)$ does not change with $d$ when $d=\psi_{2}+\psi_{1}$. Hence, the cut-off $\hat{d}$ is defined as $\hat{d}=\psi_{2}\left(a^{*}(\hat{d})+1\right)$ and $\hat{d} \in\left(\psi_{2}, \psi_{2}+\psi_{1}\right)$.

Proof of Proposition 2. The proof is given in the following steps.

Step 1: Characterization of $S$. Given a promotion cut-off $a^{*}$, the expected total surplus in period two can be written as

$$
\begin{aligned}
S\left(a^{*}\right)= & \int_{0}^{a^{*}}\left[\int_{-\infty}^{\frac{2 \psi_{1}}{\psi_{2} a^{*}}-1} \psi_{1} d G(m)+\int_{\frac{2 \psi_{1}}{\psi_{2} a^{*}}-1}^{\infty} \psi_{2} a(1+m) d G(m)\right] d a+ \\
& \int_{a^{*}}^{1}\left[\int_{-\infty}^{\frac{a-a^{*}}{a+a^{*}}} \psi_{2} a d G(m)+\int_{\frac{a-a^{*}}{a+a^{*}}}^{\infty} \psi_{2} a(1+m) d G(m)\right] d a .
\end{aligned}
$$

It is useful for the analysis that follows to characterize $S^{\prime}\left(a^{*}\right)$ and $S^{\prime \prime}\left(a^{*}\right)$. We do so for all $a^{*}<2 \psi_{1} / \psi_{2}$. Since, $a^{*}(d)<2 \psi_{1} / \psi_{2}$ for all $d$ (see the proof of Proposition $\mathbf{1}$ ), only this range of values of $a^{*}$ is relevant. Let $h_{1}\left(a, a^{*}\right)$ denote the function inside the first square brackets in the expression of $S\left(a^{*}\right)$ and $h_{2}\left(a, a^{*}\right)$ the function inside the second square brackets. Then,

$$
S^{\prime}\left(a^{*}\right)=h_{1}\left(a^{*}, a^{*}\right)+\int_{0}^{a^{*}} \frac{\partial h_{1}\left(a, a^{*}\right)}{\partial a^{*}} d a-h_{2}\left(a^{*}, a^{*}\right)+\int_{a^{*}}^{1} \frac{\partial h_{2}\left(a, a^{*}\right)}{\partial a^{*}} d a .
$$

The second term of this expression is always zero. Simplifying the other terms we obtain that

$$
\begin{aligned}
& S^{\prime}\left(a^{*}\right)= \\
& \left(\psi_{1}-a^{*} \psi_{2}\right) G(0)+\int_{0}^{\frac{2 \psi_{1}}{\psi_{2} a^{*}}-1}\left[\psi_{1}-\psi_{2} a^{*}(1+m)\right] d G(m)+\int_{a^{*}}^{1} 2 \psi_{2} g\left(\frac{a-a^{*}}{a+a^{*}}\right) \frac{a^{2}\left(a-a^{*}\right)}{\left(a+a^{*}\right)^{3}} d a .
\end{aligned}
$$

Differentiating this expression, using the fact $g$ is piecewise uniform with support in $[-1,1]$ and simplifying, we obtain that for $a^{*} \leq \psi_{1} / \psi_{2}$ (which implies that $2 \psi_{1} /\left(\psi_{2} a^{*}\right)-1 \geq 1$ ),

$$
S^{\prime \prime}\left(a^{*}\right)=\frac{1}{2} \psi_{2}(\alpha-3)+\int_{a^{*}}^{1} 2 a^{2} \psi_{2}(1-\alpha) \frac{\partial}{\partial a^{*}}\left(\frac{a-a^{*}}{\left(a+a^{*}\right)^{3}}\right) d a,
$$

and for $a^{*}>\psi_{1} / \psi_{2}$ (which implies $2 \psi_{1} /\left(\psi_{2} a^{*}\right)-1<1$ ),

$$
S^{\prime \prime}\left(a^{*}\right)=\frac{1}{2} \psi_{2}(1-3 \alpha)+\int_{a^{*}}^{1} 2 a^{2} \psi_{2}(1-\alpha) \frac{\partial}{\partial a^{*}}\left(\frac{a-a^{*}}{\left(a+a^{*}\right)^{3}}\right) d a .
$$

Both are strictly negative since by assumption $\alpha \in[1 / 2,1)$ and in both the second term is clearly negative. Thus, $S$ is concave in the interval $\left[0,2 \psi_{1} / \psi_{2}\right]$.

Step 2: Optimality of a breakup fee. Given that $S$ is concave and $a^{*}(d)$ is decreasing in $d$, setting $d>0$ in the contract is optimal (i.e., a breakup fee is optimal) if and only if $S^{\prime}\left(a^{*}(0)\right)<0$. In what follows, we show that $S^{\prime}\left(a^{*}(0)\right)<0$ if and only if $\psi_{1}$ is sufficiently high. 
We begin by showing that $S^{\prime}\left(a^{*}(0)\right)$ decreases with $\psi_{1}$. Observe that $\psi_{1}$ affects both $S^{\prime}$ (directly) and $a^{*}(0)$. Therefore,

$$
\frac{d}{d \psi_{1}} S^{\prime}\left(a^{*}(0)\right)=\frac{\partial}{\partial \psi_{1}} S^{\prime}\left(a^{*}(0)\right)+S^{\prime \prime}\left(a^{*}(0)\right) \frac{\partial}{\partial \psi_{1}} a^{*}(0)
$$

Let us analyze each term separately. Differentiating $S^{\prime}$ with respect to $\psi_{1}$ and simplifying (use (16) and focus on the case where $a^{*} \in\left(\psi_{1} / \psi_{2}, 2 \psi_{1} / \psi_{2}\right)$, since $a^{*}(0)$ is always in this interval), we obtain

$$
\frac{\partial}{\partial \psi_{1}} S^{\prime}\left(a^{*}\right)=2 \alpha-1
$$

To obtain $\partial\left(a^{*}(0)\right) / \partial \psi_{1}$, we use the condition that defines $a^{*}(0)$. Specifically, $a^{*}(0)$ is the value of $a^{*}$ that satisfies $\Pi_{N}\left(0 ; a^{*}\right)=\Pi_{P}\left(0 ; a^{*}\right)$. Using (9) and (10) in the proof of Proposition $\mathbf{1}$, this condition is given by

$$
\psi_{1} G\left(\frac{2 \psi_{1}}{\psi_{2} a^{*}}-1\right)=\psi_{2} a^{*} G(0)
$$

Using the Implicit Function Theorem, we obtain that

$$
\frac{\partial a^{*}}{\partial \psi_{1}}=\frac{G\left(\frac{2 \psi_{1}}{\psi_{2} a^{*}}-1\right)+g\left(\frac{2 \psi_{1}}{\psi_{2} a^{*}}-1\right) \frac{2 \psi_{1}}{\psi_{2} a^{*}}}{g\left(\frac{2 \psi_{1}}{\psi_{2} a^{*}}-1\right) \frac{2 \psi_{1}^{2}}{\psi_{2} a^{* 2}}+\psi_{2} G(0)}=\frac{a^{*}}{\psi_{1}},
$$

where the second equality follows from using (21) to replace $G\left(2 \psi_{1} /\left(a^{*} \psi_{2}\right)-1\right)$ with $a^{*} \psi_{2} G(0) / \psi_{1}$. Thus, $\partial a^{*}(0) / \partial \psi_{1}=a^{*}(0) / \psi_{1}$. We can now sign $\partial S^{\prime}\left(a^{*}(0)\right) / \partial \psi_{1}$. From (19) and the analysis above, we obtain that:

$$
\begin{aligned}
& \frac{\partial}{\partial \psi_{1}} S^{\prime}\left(a^{*}(0)\right)= \\
& 2 \alpha-1+\left\{\frac{1}{2} \psi_{2}(1-3 \alpha)+\int_{a^{*}(0)}^{1} 2 a^{2} \psi_{2}(1-\alpha) \frac{\partial}{\partial a^{*}(0)}\left(\frac{a-a^{*}(0)}{\left(a+a^{*}(0)\right)^{3}}\right) d a\right\} \frac{a^{*}(0)}{\psi_{1}} .
\end{aligned}
$$

Now, observe that the second term inside curly brackets is negative. Moreover, since $a^{*}(0)>$ $\psi_{1} / \psi_{2}$,

$$
2 \alpha-1+\frac{1}{2} \psi_{2}(1-3 \alpha) \frac{a^{*}(0)}{\psi_{1}}<0 .
$$

Hence, $\partial S^{\prime}\left(a^{*}(0)\right) / \partial \psi_{1}<0$ and, therefore, $S^{\prime}\left(a^{*}(0)\right)$ decreases with $\psi_{1}$.

Next, we show that $S^{\prime}\left(a^{*}(0)\right)>0$ for sufficiently low values of $\psi_{1}$ and $S^{\prime}\left(a^{*}(0)\right)<0$ for sufficiently high values of $\psi_{1}$. From $(21)$, it follows that $\lim _{\psi_{1} \rightarrow 0} a^{*}(0)=0$. From this and (16), it follows that

$$
\lim _{\psi_{1} \rightarrow 0} S^{\prime}\left(a^{*}(0)\right)=\int_{0}^{1} 2 \psi_{2} g(1) d a=2 \psi_{2}(1-\alpha)>0 .
$$

Let $\hat{\psi}_{1}$ denote the highest value of $\psi_{1}$ that satisfies Assumption 1. Observe that $a^{*}(0) \rightarrow 1$ as $\psi_{1} \rightarrow \hat{\psi}_{1}$. From this, the fact $\hat{\psi}_{1}<\psi_{2}$ and (16), it follows that

$$
\lim _{\psi_{1} \rightarrow \hat{\psi}_{1}} S^{\prime}\left(a^{*}(0)\right)=\left(\hat{\psi}_{1}-\psi_{2}\right) G(0)+\int_{0}^{\frac{2 \bar{\psi}_{1}}{\psi_{2}}-1}\left[\hat{\psi}_{1}-\psi_{2}(1+m)\right] d G(m)<0 .
$$

Since $S^{\prime}\left(a^{*}(0)\right)$ decreases with $\psi_{1}, \lim _{\psi_{1} \rightarrow 0} S^{\prime}\left(a^{*}(0)\right)>0$ and $\lim _{\psi_{1} \rightarrow \hat{\psi}_{1}} S^{\prime}\left(a^{*}(0)\right)<0$, there exists $\underline{\psi}_{1}$ such that $S^{\prime}\left(a^{*}(0)\right)<0$ (and a breakup fee is optimal) if and only if $\psi_{1}>\underline{\psi}_{1}$. 
Step 3: The value of the optimal breakup fee increases with $\psi_{1}$ for $\psi_{1}>\psi_{1}$. Suppose $\psi_{1}>\underline{\psi}_{1}$. Let $d^{*}$ denote the optimal breakup fee. Also, let $\hat{a}:=\max _{x} S(x)$. Since $S$ is differentiable, concave, $S^{\prime}(0)>0$, and $S^{\prime}\left(a^{*}(0)\right)<0$ (when $\psi_{1}>\psi_{1}$ ), we know that $S^{\prime}(\hat{a})=0$. Moreover, observe that when $\psi_{1}>\underline{\psi_{1}}$, then $\hat{a}<a^{*}(0)<2 \overline{\psi_{1}} / \psi_{2}$. We consider separately two cases regarding the value of $\hat{a}$.

Step 3.1: Suppose $\hat{a}>\psi_{1} / \psi_{2}$. The optimal breakup fee $d^{*}$ satisfies $a^{*}\left(d^{*}\right)=\hat{a}$ and by Proposition $1, d^{*}<\psi_{1}$. Hence, $d^{*}$ satisfies $S^{\prime}\left(a^{*}\left(d^{*}\right)\right)=0$. This condition is used to characterize how $d^{*}$ changes with $\psi_{1}$. In particular, since $S$ is concave and $a^{*}(d)$ is decreasing in $d$, then $d^{*}$ increases with $\psi_{1}$ if $S^{\prime}\left(a^{*}\left(d^{*}\right)\right)$ decreases with $\psi_{1}$. We next show that indeed $S^{\prime}\left(a^{*}\left(d^{*}\right)\right)$ decreases with $\psi_{1}$. Since $\psi_{1}$ affects $S^{\prime}$ directly and $a^{*}\left(d^{*}\right)$, then

$$
\frac{\partial}{\partial \psi_{1}} S^{\prime}\left(a^{*}\left(d^{*}\right)\right)=\frac{\partial}{\partial \psi_{1}} S^{\prime}\left(a^{*}\left(d^{*}\right)\right)+S^{\prime \prime}\left(a^{*}\left(d^{*}\right)\right) \frac{\partial}{\partial \psi_{1}} a^{*}\left(d^{*}\right)
$$

The terms $\frac{\partial S^{\prime}}{\partial \psi_{1}}$ and $S^{\prime \prime}$ are given by (20) and (18), respectively. We next characterize $\partial a^{*}\left(d^{*}\right) / \partial \psi_{1}$. The cutoff $a^{*}(d)$ is defined as the value of $a^{*}$ that satisfies $\Pi_{N}\left(0 ; a^{*}\right)=$ $\Pi_{P}\left(0 ; a^{*}\right)$. Using (9) and (10) in the proof of Proposition 1 it is easy to obtain that when $d<\psi_{1}$ this condition is given by

$$
\psi_{1} G\left(\frac{2 \psi_{1}}{\psi_{2} a^{*}}-1\right)+d\left[1-G\left(\frac{2 \psi_{1}}{\psi_{2} a^{*}}-1\right)\right]=a^{*} \psi_{2} G(0)+d[1-G(0)] .
$$

By the Implicit Function Theorem, we obtain that:

$$
\frac{\partial a^{*}(d)}{\partial \psi_{1}}=\frac{a^{*}}{\psi_{1}} \times\left\{\frac{G\left(\frac{2 \psi_{1}}{\psi_{2} a^{*}}-1\right)+g\left(\frac{2 \psi_{1}}{\psi_{2} a^{*}}-1\right) \frac{2 \psi_{1}}{\psi_{2} a^{*}}-g\left(\frac{2 \psi_{1}}{\psi_{2} a^{*}}-1\right) \frac{2 d}{\psi_{2} a^{*}}}{g\left(\frac{2 \psi_{1}}{\psi_{2} a^{*}}-1\right) \frac{2 \psi_{1}}{\psi_{2} a^{*}}-g\left(\frac{2 \psi_{1}}{\psi_{2} a^{*}}-1\right) \frac{2 d}{\psi_{2} a^{*}}+a^{*} \frac{\psi_{2}}{\psi_{1}} G(0)}\right\}>\frac{a^{*}}{\psi_{1}},
$$

where the inequality follows from the fact that the term inside the curly brackets is greater than one. To see this, note that the only difference between the numerator and the denominator of that expression is the first term of the former and the last term of the latter, and that by $(23)$

$$
G\left(\frac{2 \psi_{1}}{\psi_{2} a^{*}}-1\right)=a^{*} \frac{\psi_{2}}{\psi_{1}} G(0)+\frac{d}{\psi_{1}}\left[G\left(\frac{2 \psi_{1}}{\psi_{2} a^{*}}-1\right)-G(0)\right]>a^{*} \frac{\psi_{2}}{\psi_{1}} G(0)
$$

where the last inequality follows from the fact that $2 \psi_{1} /\left(\psi_{2} a^{*}\right)-1>0$ since we know that $a^{*}(d)<2 \psi_{1} / \psi_{2}$ (see proof of Proposition 1). Given the above, we can write $(24)$

$$
\begin{aligned}
& \frac{\partial}{\partial \psi_{1}} S^{\prime}\left(a^{*}\left(d^{*}\right)\right)=2 \alpha-1+\left\{\frac{1}{2} \psi_{2}(1-3 \alpha)+\int_{a^{*}}^{1} 2 a^{2} \psi_{2}(1-\alpha) \frac{\partial}{\partial a^{*}}\left(\frac{a-a^{*}}{\left(a+a^{*}\right)^{3}}\right) d a\right\} \frac{\partial a^{*}\left(d^{*}\right)}{\partial \psi_{1}} \\
& \leq 2 \alpha-1+\left\{\frac{1}{2} \psi_{2}(1-3 \alpha)+\int_{a^{*}}^{1} 2 a^{2} \psi_{2}(1-\alpha) \frac{\partial}{\partial a^{*}}\left(\frac{a-a^{*}}{\left(a+a^{*}\right)^{3}}\right) d a\right\} \frac{a^{*}}{\psi_{1}} \\
& <2 \alpha-1+\left\{\frac{1}{2} \psi_{2}(1-3 \alpha)\right\} \frac{a^{*}}{\psi_{1}} \\
& <2 \alpha-1+\left\{\frac{1}{2} \psi_{2}(1-3 \alpha)\right\} \frac{1}{\psi_{2}}<0,
\end{aligned}
$$

where the first inequality follows from the fact that the term inside curly brackets is negative (since $S^{\prime \prime}<0$ ) and $\partial a^{*}\left(d^{*}\right) / \partial \psi_{1}>a^{*} / \psi_{1}$ while positive, the second from the fact that the second term inside curly brackets is negative, and the third from the fact that $a^{*}\left(d^{*}\right)=\hat{a}>$ $\psi_{1} / \psi_{2}$. 
Step 3.2: Suppose $\hat{a}<\psi_{1} / \psi_{2}$. The proof is similar to that of the case when $\hat{a}>$ $\psi_{1} / \psi_{2}$ analyzed in the previous step. Again, we show that $\partial S^{\prime}\left(a^{*}\left(d^{*}\right)\right) / \partial \psi_{1}<0$. The difference relative to that case is that now $d^{*}>\psi_{1}$, which implies that the terms in (22) are (quantitatively) different. Specifically, since we are analyzing cases where $a^{*}<\psi_{1} / \psi_{2}$ (which implies that $2 \psi_{1} /\left(a^{*} \psi_{2}\right)-1>1$ ), we have

$$
\frac{\partial}{\partial \psi_{1}} S^{\prime}\left(a^{*}\left(d^{*}\right)\right)=G(0)+\int_{0}^{1} d G(m)=1
$$

and $S^{\prime \prime}$ is given by (17). Regarding $\partial a^{*}\left(d^{*}\right) / \partial \psi_{1}$, following the same procedure as in the previous step, we obtain that it is greater than $a^{*}\left(d^{*}\right) / \psi_{1}$ while positive. Given this, for all $d^{*}>\psi_{1}$,

$$
\begin{aligned}
& \frac{\partial}{\partial \psi_{1}} S^{\prime}\left(a^{*}(d)\right)=1+\left\{\frac{1}{2} \psi_{2}(\alpha-3)+\int_{a^{*}}^{1} 2 a^{2} \psi_{2}(1-\alpha) \frac{\partial}{\partial a^{*}}\left(\frac{a-a^{*}}{\left(a+a^{*}\right)^{3}}\right) d a\right\} \frac{\partial a^{*}(d)}{\partial \psi_{1}} \\
& \leq 1+\left\{\frac{1}{2} \psi_{2}(\alpha-3)+\int_{a^{*}}^{1} 2 a^{2} \psi_{2}(1-\alpha) \frac{\partial}{\partial a^{*}}\left(\frac{a-a^{*}}{\left(a+a^{*}\right)^{3}}\right) d a\right\} \frac{a^{*}}{\psi_{1}} \\
& =1+\left\{\frac{1}{2} \psi_{2}(\alpha-3)-\psi_{2}(1-\alpha) \int_{a^{*}}^{1} 4 a^{2} \frac{2 a-a^{*}}{\left(a+a^{*}\right)^{4}} d a\right\} \frac{a^{*}}{\psi_{1}} .
\end{aligned}
$$

We next show this is negative. We begin by simplifying the second term inside the curly brackets. Define, $H(a):=(1-\alpha) 2 a^{2} \psi_{2}\left(a-a^{*}\right) /\left(a+a^{*}\right)^{3}$ and let $h(a)=H^{\prime}(a)$. Observe that

$$
-\psi_{2}(1-\alpha) \int_{a^{*}}^{1} 4 a^{2} \frac{2 a-a^{*}}{\left(a+a^{*}\right)^{4}} d a=-\frac{1}{a^{*}} \int_{a^{*}}^{1} a h(a) d a .
$$

Using the rule of integration by parts (which implies that $\int_{a^{*}}^{1} H(a) d a=[a H(a)]_{a^{*}}^{1}-\int_{a^{*}}^{1} a h(a) d a$ ) and the fact that $[a H(a)]_{a^{*}}^{1}=2(1-\alpha) \psi_{2}\left(1-a^{*}\right) /\left(1+a^{*}\right)^{3}$, we obtain

$$
-\psi_{2}(1-\alpha) \int_{a^{*}}^{1} 4 a^{2} \frac{2 a-a^{*}}{\left(a+a^{*}\right)^{4}} d a=\frac{1}{a^{*}}\left\{\int_{a^{*}}^{1} H(a) d a-\frac{2(1-\alpha) \psi_{2}\left(1-a^{*}\right)}{\left(1+a^{*}\right)^{3}}\right\} .
$$

Now, observe that $\int_{a^{*}}^{1} H(a) d a$ is identical to last term of (16). Thus, from the fact that $S^{\prime}\left(a^{*}\left(d^{*}\right)\right)=0$, it follows that when $a^{*}=a^{*}\left(d^{*}\right)$,

$$
\begin{aligned}
& \int_{a^{*}}^{1} 2 \psi_{2}(1-\alpha) a^{2} \frac{\partial}{\partial a^{*}}\left(\frac{a-a^{*}}{\left(a+a^{*}\right)^{3}}\right) d a= \\
& -\frac{1}{a^{*}}\left\{\frac{1}{2}\left(2 \psi_{1}-3 \psi_{2} a^{*}+\alpha \psi_{2} a^{*}\right)+2(1-\alpha) \psi_{2} \frac{1-a^{*}}{\left(1+a^{*}\right)^{3}}\right\} .
\end{aligned}
$$

Using this in (24) and simplifying, we obtain that the expression in (24) is strictly negative if and only if

which is indeed the case.

$$
-2(1-\alpha) \psi_{2} \frac{1-a^{*}}{\left(1+a^{*}\right)^{3}}<0
$$

Proof of Proposition 3. The proof is given in two steps. In the first we prove part $(i)$ of the Proposition and in the second part $(i i)$.

Step 1: The promotion cutoff $a^{*}(d)$ decreases with $\alpha$ when $d<\psi_{1}$ and increases with $\alpha$ otherwise. The promotion cutoff $a^{*}(d)$ is the value $a^{*}$ such that $\Pi_{N}\left(d ; a^{*}\right)=\Pi_{P}\left(d ; a^{*}\right)$. When $d<\psi_{1}$, this condition is given by (use (9) and (10) in the proof of Proposition 1)

$$
\left(\psi_{1}-d\right)\left(\alpha+(1-\alpha)\left(\frac{2 \psi_{1}}{\psi_{2} a^{*}}-1\right)\right)=\left(\psi_{2} a^{*}-d\right) \alpha
$$


Using the Implicit Function Theorem and using (25) again to simplify the expression obtained, we get

$$
\frac{\partial a^{*}(d)}{\partial \alpha}=\frac{a^{*}}{1-\alpha} \times \frac{\psi_{1}-\psi_{2} a^{*}}{\psi_{1}-2 \alpha\left(\psi_{1}-\psi_{2} a^{*}\right)-d(1-\alpha)},
$$

which is negative, since the numerator in the second fraction is negative and the denominator is positive because $d<\psi_{1}$ and because by Proposition 1, $a^{*}(d)>\psi_{1} / \psi_{2}$ when $d<\psi_{1}$.

Consider now the case where $\psi_{1}<d<\psi_{2}$. In this case, $\Pi_{N}\left(d ; a^{*}\right)=\Pi_{P}\left(d ; a^{*}\right)$ is given by

$$
\psi_{1}=\alpha \psi_{2} a^{*}+(1-\alpha) \int_{0}^{\frac{d-\psi_{2} a^{*}}{d+\psi_{2} a^{*}}} \psi_{2} a^{*} \frac{1+m}{1-m} d m+(1-\alpha) d\left(1-\frac{d-\psi_{2} a^{*}}{d+\psi_{2} a^{*}}\right) .
$$

Using the same procedure as above, we obtain that

$$
\frac{\partial}{\partial \alpha} a^{*}(d)=\left(\psi_{1}-\psi_{2} a^{*}\right) /\left[\alpha(1-\alpha) \psi_{2} a^{*}+\int_{0}^{\frac{d-\psi_{2} a^{*}}{d+\psi_{2} a^{*}}}(1-\alpha)^{2} \psi_{2} a^{*} \frac{1+m}{1-m} d m\right],
$$

Finally, when $d>\psi_{2}, \Pi_{N}\left(d ; a^{*}\right)=\Pi_{P}\left(d ; a^{*}\right)$ is given by

$$
\begin{aligned}
\psi_{1}= & \alpha \psi_{2} a^{*}+(1-\alpha) \int_{0}^{\frac{1-a^{*}}{1+a^{*}}} \psi_{2} a^{*} \frac{1+m}{1-m} d m \\
& +(1-\alpha) \int_{\frac{1-a^{*}}{1+a^{*}}}^{\frac{2 d}{\left.\psi^{*}+a^{*}\right)}}-1 \frac{a^{*}+1}{2} \psi_{2}(1+m) d m+2(1-\alpha) d\left(1-\frac{d}{\psi_{2}\left(1+a^{*}\right)}\right) .
\end{aligned}
$$

Following again the same procedure as above,

$$
\begin{aligned}
& \frac{\partial}{\partial \alpha} a^{*}(d)= \\
& \left(\psi_{1}-\psi_{2} a^{*}\right) /\left[\alpha(1-\alpha) \psi_{2}+\int_{0}^{\frac{1-a^{*}}{1+a^{*}}}(1-\alpha)^{2} \psi_{2} \frac{1+m}{1-m} d m+\int_{\frac{1-a^{*}}{1+a^{*}}}^{\frac{2 d}{(1+)^{*}}-1} \frac{1}{2}(1-\alpha)^{2} \psi_{2}(1+m) d m\right],
\end{aligned}
$$

Note that in both cases above, the derivative is positive, since the denominators are positive and by Proposition $1, a^{*}(d)<\psi_{1} / \psi_{2}$ when $d>\psi_{1}$.

Step 2: The threshold $\psi_{1}$ is decreasing in $\alpha$. The threshold $\underline{\psi}_{1}$ is the value of $\psi_{1}$ for which $S^{\prime}\left(a^{*}(0)\right)=0$. Since $S^{\prime}\left(a^{*}(0)\right)$ decreases with $\psi_{1}$ (see Step 2 of the proof of Proposition 2 ), to prove that $\underline{\psi}_{1}$ is decreasing in $\alpha$, it suffices to show that $\partial S^{\prime}\left(a^{*}(0)\right) / \partial \alpha<0$ when $\psi_{1}=\underline{\psi}_{1}$.

Since $\alpha$ affects $S^{\prime}$ directly and $a^{*}\left(d^{*}\right)$, then

$$
\frac{d}{d \alpha} S^{\prime}\left(a^{*}(0)\right)=\frac{\partial}{\partial \alpha} S^{\prime}\left(a^{*}(0)\right)+S^{\prime \prime}\left(a^{*}(0)\right) \frac{\partial a^{*}(0)}{\partial \alpha},
$$

Next, we characterize each of the components of this expression. From (16) in the proof of Proposition 2, we obtain

$$
\begin{aligned}
S^{\prime}\left(a^{*}\right)= & \left(\psi_{1}-\psi_{2} a^{*}\right) \alpha+(1-\alpha) \int_{0}^{\frac{2 \psi_{1}}{\psi_{2} a^{*}}-1}\left[\psi_{1}-\psi_{2} a^{*}(1+m)\right] d m \\
& +\int_{a^{*}}^{1} 2(1-\alpha) \psi_{2} a^{2} \frac{a-a^{*}}{\left(a+a^{*}\right)^{3}} d a .
\end{aligned}
$$

Differentiating this expression with respect to $\alpha$ and using condition $S^{\prime}\left(a^{*}(0)\right)=0$, we obtain that when $a^{*}=a^{*}(0)$,

$$
\frac{\partial}{\partial \alpha} S^{\prime}\left(a^{*}\right)=\frac{\psi_{1}-\psi_{2} a^{*}}{1-\alpha}
$$


From (26) in Step 1, we obtain that

$$
\frac{\partial a^{*}(0)}{\partial \alpha}=\frac{a^{*}(0)}{1-\alpha} \times \frac{\psi_{1}-\psi_{2} a^{*}(0)}{\psi_{1}-2 \alpha\left(\psi_{1}-\psi_{2} a^{*}(0)\right)}
$$

and is negative.

From (27), (29), (18) in the proof of Proposition 2 and (30), we obtain that:

$$
\begin{aligned}
& \frac{\partial}{\partial \alpha} S^{\prime}\left(a^{*}(0)\right)= \\
& \frac{\psi_{1}-\psi_{2} a^{*}}{1-\alpha}\left[1+\left\{\frac{1}{2} \psi_{2}(1-3 \alpha)+\int_{a^{*}}^{1} 2 \psi_{2}(1-\alpha) a^{2} \frac{\partial}{\partial a^{*}}\left(\frac{a-a^{*}}{\left(a+a^{*}\right)^{3}}\right) d a\right\} \frac{a^{*}}{\psi_{1}-2 \alpha\left(\psi_{1}-\psi_{2} a^{*}\right)}\right] .
\end{aligned}
$$

Observe that $\left(\psi_{1}-a^{*} \psi_{2}\right)<0$ since $a^{*}(0)>\psi_{1} / \psi_{2}$. Hence, to show that $\partial S^{\prime}\left(a^{*}(0)\right) / \partial \alpha$, we only need to show that term inside the square brackets is positive. Since $\psi_{1}-2 \alpha\left(\psi_{1}-a^{*} \psi_{2}\right)>$ 0 (recall that $\left.a^{*}(0)>\psi_{1} / \psi_{2}\right)$, this is equivalent to showing that

$$
\psi_{1}-2 \alpha\left(\psi_{1}-\psi_{2} a^{*}\right)+\left\{\frac{1}{2}(1-3 \alpha) \psi_{2}-(1-\alpha) \psi_{2} \int_{a^{*}}^{1} 4 a^{2} \frac{2 a-a^{*}}{\left(a+a^{*}\right)^{4}} d a\right\} a^{*}>0
$$

Using a procedure identical to that used in Step 3.2 of the proof of Proposition 2 (integration by parts combined with condition $S^{\prime}\left(a^{*}(0)\right)=0$ ), we obtain that

$$
-(1-\alpha) \psi_{2} \int_{a^{*}}^{1} 4 a^{2} \frac{2 a-a^{*}}{\left(a+a^{*}\right)^{4}} d a=\frac{1}{2 a^{*}}\left((2-4 \alpha) \psi_{1}-(1-3 \alpha) \psi_{2} a^{*}\right)-\frac{2(1-\alpha) \psi_{2}\left(1-a^{*}\right)}{a^{*}\left(1+a^{*}\right)^{3}} .
$$

Using this in (32) and simplifying, we obtain that condition is equivalent to

$$
-(2 \alpha-1) \psi_{1}+\alpha \psi_{2} a^{*}-\frac{\left(1-a^{*}\right)(1-\alpha)}{\left(a^{*}+1\right)^{3}} \psi_{2}>0 .
$$

Using again condition $S^{\prime}\left(a^{*}\right)=0$ to eliminate the term with $\psi_{1}$, we obtain that (??) is equivalent to

$$
\frac{1}{2} a^{*}+\int_{a^{*}}^{1} 2 a^{2} \frac{a-a^{*}}{\left(a+a^{*}\right)^{3}} d a-\frac{1-a^{*}}{\left(a^{*}+1\right)^{3}}>0,
$$

which holds for all $a^{*} \in[0,1]$ and therefore for $a^{*}=a^{*}(0)$. Hence the proof.

\section{REFERENCES}

[1] Aghion, P., and P. Bolton. (1987) "Contracts as a Barrier to Entry," The American Economic Review, Vol. 77 , pp. 388-401.

[2] Allen, S., Clark, R., and A. McDermed. (1993) "Pensions, bonding, and lifetime jobs." The Journal of Human Resources, Vol. 28, pp. 463-481.

[3] Becker, G. (1964) "Human Capital." University of Chicago Press: Chicago.

[4] Baker, G., M. Gibbs, and B. Holmstrom (1994a) "The Wage Policy of a Firm." Quarterly Journal of Economics, Vol. 109, pp. 881-919.

[5] _ . . _ . and _ . (1994b) "The Internal Economics of the Firm: Evidence from Personnel Data." Quarterly Journal of Economics, Vol. 109, pp. 921-955.

[6] Bernhardt, D., and D. Scoones. (1993) "Promotion, Turnover, and Preemptive Wage Offers," American Economic Review, Vol. 83, pp. 771-791.

[7] —., and —. (1998) "Promotion, Turnover, and Discretionary Human Capital Acquisition," Journal of Labor Economics, Vol. 16, pp. 122-141.

[8] Bishara, N. (2006) "Covenants not-to-Compete in a Knowledge Economy: Balancing Innovation from Employee Mobility Against Legal Protection for Human Capital Investment," Berkeley Journal of Employment $\mathcal{E}_{3}$ Labor Law, Vol. 27, pp. 289-325. 
[9] Bognanno, M. and Melero, E. (2016) "Promotion Signals, Experience, and Education," Journal of Economics 83 Management Strategy, Vol. 25, pp. 111-132.

[10] Burguet, R., Caminal, R., and C. Matutes. (2002): "Golden Cages for Showy Birds: Optimal Switching Costs in Labor Contracts," European Economic Review, Vol. 46, pp. 1153-85.

[11] Cassidy, H., J. ex-ante, and A. Kauhanen. (2016) "Promotion Signaling, Gender, and Turnover: New Theory and Evidence." Journal of Economic Behavior \&3 Organization, Vol. 126, pp. 140-166.

[12] Dato, S., A. Grunewald, M. Kräkel, and D. Müller. (2016) "Asymmetric Employer Information, Promotions, and the Wage Policy of Firms." Games and Economic Behavior, Vol. 100, pp. 273-300.

[13] DeVaro, J., Ghosh, S., and C. Zoghi. (forthcoming) "Job Characteristics and Labor Market Discrimination in Promotions." Industrial Relations.

[14] _ . and M. Waldman. (2012) "The Signaling Role of Promotions: Further Theory and Empirical Evidence," Journal of Labor Economics, Vol. 30, pp. 91-147.

[15] Franco, A., and D. Filson. (2006) "Spin-Outs: Knowledge Diffusion through Employee Mobility," RAND Journal of Economics, Vol. 37, pp. 841-60.

[16] _., and M. Mitchell. (2008) "Covenants not-to-Compete, Labor Mobility, and Industry Dynamics," Journal of Economics and Management Strategy, Vol. 17, pp. 581-606.

[17] Fudenberg, D. and J. Tirole. Game Theory. The MIT Press, Cambridge, Massachusetts. Seventh printing, 2000.

[18] Garmaise, M. (2011) "Ties that Truly Bind: Noncompetition Agreements, Executive Compensation, and Firm Investment," Journal of Law Economics and Organization, Vol. 27, pp. 376-425.

[19] Gibbons, R., and L. Katz. (1991) "Layoffs and Lemons," Journal of Labor Economics, 9(4), pp. 351-380.

[20] —.., and M. Waldman. (1999) "Careers in Organizations: Theory and Evidence." Chapter 36 in Volume 3B of O. Ashenfelter and D. Card (eds.), Handbook of Labor Economics, North Holland.

[21] Ghosh, S., and M. Waldman. (2010) "Standard Promotion Practices versus Up-or-out Contracts," RAND Journal of Economics, Vol 41, pp. 301-325.

[22] Golan, L. (2005) "Counteroffers and Efficiency in Labor Markets with Asymmetric Information," Journal of Labor Economics, Vol. 23, pp. 373-393.

[23] Greenwald, B. (1986) "Adverse Selection in Labor Market," Review of Economic Studies, Vol. 53, pp. $325-347$.

[24] Hoffman, M., and S. Burks. (2013) "Training Contracts, Worker Overconfidence, and the Provision of Firm-Sponsored General Training." Mimeo, University of Toronto.

[25] Jackson, M., and E. Lazear. (1991) "Stocks, Options, and Deferred Compensation," Research in Labor Economics, Vol. 12, pp. 41-62.

[26] Koch, A. K. and E. Peyrache. (2011) "Aligning Ambition and Incentives," Journal of Law, Economics $\&$ Organization, Vol. 27, pp. 655-688.

[27] Kräkel, M., and D. Sliwka. (2009) "Should you Allow your Agent to Become your Competitor? On noncompete Agreement in Employment Contracts," International Economic Review, Vol. 50, pp. 117-141.

[28] Laing, D. (1994) "Involuntary Layoff in a Model with Asymmetric Information Concerning Worker Ability," Review of Economic Studies, Vol. 61, pp. 375-392.

[29] Lazear, E. (1979) "Why is There Mandatory Retirement?" Journal of Political Economy, Vol. 87 (6), pp. 1261-84.

[30] —. (1986) "Raids and Offer Matching." In R. Ehrenberg, eds., Research in Labor Economics, Vol 8. Greenwich, Conn.: JAI.

[31] Lobel, O. (2013) "Talent Wants to Be Free: Why We Should Learn to Love Leaks, Raids, and FreeRiding." Yale University Press, New Haven.

[32] Loveman, W., and J. O'Connell. (1996) "HCL America." Harvard Business Review, Case \# 9-396-030.

[33] Malsberger, B. (2004) "Covenants not to Compete: A State-by-State Survey." Washington, DC: BNA Books.

[34] Manchester, C. (2009) "How Does General Training Increase Retention? Examination Using Tuition Reimbursement Programs." Mimeo, University of Minnesota.

[35] McCue, K. (1996) "Promotions and Wage Growth," Journal of Labor Economics, Vol. 14, pp. 175-209.

[36] Mehran, H., and D. Yermack. (1997) "Compensation and top Management Turnover." New York University, Department of Finance Working paper series No. FIN 98-051. 
[37] Milgrom, P., and S. Oster. (1987) "Job Discrimination, Market Forces, and the Invisibility Hypothesis." The Quarterly Journal of Economics, Vol. 102, pp. 453-476.

[38] Mukherjee, A. (2008) "Career Concerns, Matching, and Optimal Disclosure Policy," International Economic Review, Vol. 49, pp. 1211-1250.

[39] — , and L. Vasconcelos. (2012) "Star Wars: Exclusive Talent and Collusive Outcomes in Labor Markets," Journal of Law Economics 83 Organization, Vol. 28, pp. 754-782.

[40] — and - (2015) "On the trade-off between efficiency in job assignment and turnover: the role of breakup fees." Working paper, SSRN: https://ssrn.com/abstract=3014973.

[41] Posner, E., Triantis, A. and G. Triantis (2004) "Investing in Human Capital: The Efficiency of Covenants Not to Compete," University of Chicago Law 83 Economics, Olin Working Paper No. $13 \%$.

[42] Rauch, J., and J. Watson (2015) "Client-Based Entrepreneurship," Journal of Law Econmics $\mathscr{E}$ Organization, Vol. 31, pp. 30-60.

[43] Ricart i Costa, J. (1988) "Managerial Task Assignment and Promotions," Econometrica Vol. 56, pp. 449-466.

[44] Rubin, P., and P. Shedd. (1981) "Human Capital and Covenants not to Compete," Journal of Legal Studies, Vol. 10, pp. 93-110.

[45] Salop, J., and S. Salop. (1976) "Self-selection and Turnover in the Labor Market," Quarterly Journal of Economics, Vol. 90, pp. 619-627.

[46] Scholes, M. (1991) "Stock and Compensation," Journal of Finance, Vol. 46, pp. 803-823.

[47] Spier, K., and M. Whinston. (1995) "On the Efficiency of Privately Stipulated Damages for Breach of Contract: Entry Barriers, Reliance, and Renegotiation," RAND Journal of Economics, Vol. 26, pp. 180-202.

[48] Waldman, M. (1984) "Job Assignments, Signalling, and Efficiency Job Assignments, Signalling, and Efficiency," RAND Journal of Economics, Vol. 15, pp. 255-267.

[49] — (1990) "Up-or-Out Contracts: A Signaling Perspective," Journal of Labor Economics, Vol. 8, pp. $230-250$.

[50] - (2013) "Classic promotion tournaments versus market-based tournaments," International Journal of Industrial Organization, Vol. 31, p. 198-210.

[51] — and O. Zax. (2016) "An Exploration of the Promotion Signal Distortion." The Journal of Law, Economics, and Organization, Vol. 32, pp. 119-149.

[52] Watson, J. (2016) "Perfect Bayesian Equilibrium: General Definitions and Illustrations." Mimeo, UC San Diego.

[53] Zábojník, J., and D. Bernhardt. (2001) "Corporate Tournaments, Human Capital Acquisition, and the Firm Size-wage Relation." Review of Economic Studies, Vol 68, pp. 693-716. 